\title{
HURRICANES AND CLIMATE The U.S. CLIVAR Working Group on Hurricanes
}

\author{
by Kevin J. E. Walsh, Suzana J. Camargo, Gabriel A. Vecchi, Anne Sophie Daloz, James Elsner, \\ Kerry Emanuel, Michael Horn, Young-Kwon lim, Malcolm Roberts, Christina Patricola, \\ Enrico Scoccimarro, Adam H. Sobel, Sarah Strazzo, Gabriele Villarini, Michael Wehner, \\ Ming Zhao, James P. Kossin, Tim LaRow, Kazuyoshi Oouchi, Siegfried Schubert, Hui Wang, \\ Julio Bacmeister, Ping Chang, Fabrice Chauvin, Christiane Jablonowski, Arun Kumar, \\ Hiroyuki Murakami, Tomoakı Ose, Kevin A. Reed, Ramalingam Saravanan, Yohei Yamada, \\ Colin M. Zarzycki, Pier luigi Vidale, Jeffrey A. Jonas, and Naomi Henderson
}

Although a theory of the climatology of tropical cyclone formation remains elusive, high-resolution climate models can now simulate many aspects of tropical cyclone climate.

$\mathrm{T}$ he effect of climate change on tropical cyclones has been a controversial scientific issue for a number of years. Advances in our theoretical understanding of the relationship between climate and tropical cyclones have been made, enabling us to understand better the links between the mean climate and the potential intensity (PI; the theoretical maximum intensity of a tropical cyclone for a given climate condition) of tropical cyclones. Improvements in the capabilities of climate models, the main tool used to predict future climate, have enabled them to achieve a considerably improved and more credible simulation of the present-day climatology of tropical cyclones. Finally, the increasing ability of such models to predict the interannual variability of tropical cyclone formation in various regions of the globe indicates that they are capturing some of the essential physical relationships governing the links between climate and tropical cyclones.

Previous climate model simulations, however, have suggested some ambiguity in projections of future numbers of tropical cyclones in a warmer world. While many models have projected fewer tropical cyclones globally (Sugi et al. 2002; Bengtsson et al. 2007b; Gualdi et al. 2008; Knutson et al. 2010), other climate models and related downscaling methods have suggested some increase in future numbers (e.g., Broccoli and Manabe 1990; Haarsma et al. 1993; Emanuel 2013a). When future projections for individual basins are made, the issue becomes more serious: for example, for the Atlantic basin there appears to be little consensus on the future number of tropical cyclones (Knutson et al. 2010) or on the relative importance of forcing factors such as aerosols or increases in carbon dioxide $\left(\mathrm{CO}_{2}\right)$ concentration. One reason could be statistical: annual numbers of tropical cyclones in the Atlantic are relatively small, making the identification of such storms sensitive to the detection method used.

Further, there is substantial spread in projected responses of regional tropical cyclone (TC) frequency and intensity over the twenty-first century from downscaling studies (Knutson et al. 2007; Emanuel 2013a). Interpreting the sources of those differences is complicated by different projections of large-scale climate and by differences in the present-day reference period and sea surface temperature (SST) datasets used. A natural question is whether the diversity in responses to projected twenty-firstcentury climate of each of the studies is primarily 
a reflection of uncertainty arising from different large-scale forcing (as has been suggested by, e.g., Villarini et al. 2011; Villarini and Vecchi 2012; Knutson et al. 2013) or whether this spread reflects principally different inherent sensitivities across the various downscaling techniques, even including different sensitivity of responses within the same model due to, for instance, the use of different convective parameterizations (Kim et al. 2012). A similar set of questions relates to the ability of models to generate observed changes in TC statistics when forced with a common forcing dataset.

The preceding questions motivated the design of a number of common idealized experiments to be simulated by different atmospheric general circulation models. Following on from experiments described

AFFILIATIONS: WALSH AND HORN-University of Melbourne, Parkville, Victoria, Australia; Camargo, Sobel, and HendersonLamont-Doherty Earth Observatory, Columbia University, Palisades, New York; Vecchi, Zhao, and MurakamiGeophysical Fluid Dynamics Laboratory, Princeton, New Jersey; DALOZ-Space Science and Engineering Center, University of Wisconsin-Madison, Madison, Wisconsin; ELSNER, Strazzo, AND LARow-Florida State University, Tallahassee, Florida; EMANUELMassachusetts Institute of Technology, Cambridge, Massachusetts LIM-Global Modeling and Assimilation Office, NASA Goddard Space Flight Center, and Goddard Earth Sciences Technology and Research, and I. M. Systems Group, Greenbelt, Maryland; Roberts-Met Office, Exeter, United Kingdom; Patricola, Chang, and Saravanan-Texas A\&M University, College Station, Texas; Scoccimarro-Istituto Nazionale di Geofisica e Vulcanologia, and Centro Euro-Mediterraneo sui Cambiamenti Climatici, Bologna, Italy; VILLARINI-University of lowa, lowa City, lowa; WeHNERLawrence Berkeley National Laboratory, Berkeley, California; KossIN-NOAA/NCDC, Asheville, North Carolina; OoucHI AND YAMADA-JAMSTEC, Yokohama, Kanagawa, Japan; SCHUBERTGlobal Modeling and Assimilation Office, NASA Goddard Space Flight Center, Greenbelt, Maryland; WANG AND KUMAR-NOAA/ NCEP, College Park, Maryland; Bacmeister And Reed—National Center for Atmospheric Research, Boulder, Colorado; Chauvin-Météo-France, Toulouse, France; JABLONOWSKI AND ZARZYCKI-University of Michigan, Ann Arbor, Michigan; OSEMeteorological Research Institute, Japan Meteorological Agency, Tsukuba-city, Ibaraki, Japan; VIDALE-University of Reading, Reading, United Kingdom; JoNAs-NASA Goddard Institute for Space Studies, and Columbia University, New York, New York CORRESPONDING AUTHOR: Kevin Walsh, School of Earth Sciences, University of Melbourne, Parkville VIC 30I0, Australia E-mail: kevin.walsh@unimelb.edu.au

The abstract for this article can be found in this issue, following the table of contents.

DOI:10.1175/BAMS-D-13-00242.I

In final form 15 September 2014

(C2015 American Meteorological Society in Yoshimura and Sugi (2005), Held and Zhao (2011) have designed a series of experiments using the High Resolution Atmospheric Model (HiRAM): using present-day climatological, seasonally varying monthly SSTs (i.e., the same climatological monthly average seasonal cycle of SSTs repeating every year; the "climo" experiment); specifying interannually varying monthly SSTs (monthly SSTs that vary from year to year, as observed; "amip"); applying a uniform warming of $2 \mathrm{~K}$ added to the climatological SST values (“2K"); employing SSTs at their climatological values but where the $\mathrm{CO}_{2}$ concentration was doubled in the atmosphere ("2 $\mathrm{CO} 2$ "); and combining a uniform $2 \mathrm{~K}$ SST increase and doubled carbon dioxide ("2 $2 \mathrm{~K} 2 \mathrm{CO} 2$ "). The purpose of these common experiments is to determine whether responses would be robust across a number of different, high-resolution climate models (see Table 1). This would then establish better relationships between climate forcings and tropical cyclone occurrence, a key goal in work toward the development of a climate theory of tropical cyclone formation. To facilitate this goal, U.S. Climate and Ocean: Variability, Predictability and Change (CLIVAR) established the Hurricane Working Group (HWG). Another goal of this group is to provide a synthesis of current scientific understanding of this topic. The following sections summarize our understanding of climate controls on tropical cyclone formation and intensity and the results of the HWG experiments analyzed to date, as well as other issues such as tropical cyclone rainfall. The focus of this work is on tropical cyclone formation, owing to the very fine horizontal resolutions needed to generate good simulations of tropical cyclone climatological intensity distributions. A concluding section outlines avenues for further research.

TROPICAL CYCLONE FORMATION. At present, there is no climate theory that can predict the formation rate of tropical cyclones from the mean climate state. It has been known for many years that there are certain atmospheric conditions that either promote or inhibit the formation of tropical cyclones, but so far an ability to relate these quantitatively to mean rates of tropical cyclone formation has not been achieved, other than by statistical means through the use of semiempirically based genesis potential indices (GPIs; see, for instance, Menkes et al. 2012). Increasingly, numerical models of the atmosphere are being used to pose the kind of questions that need to be answered to address this issue.

The ability of climate models to simulate the presentday tropical cyclone climatology. A starting point for 
TABLE I. List of participating modeling centers, models, horizontal resolution, and experiments performed. COAPS: Center for Ocean-Atmospheric Prediction Studies. CI80AM2: Geophysical Fluid Dynamics Laboratory Atmospheric Climate Model, Cl80 resolution. HG3-N216: Hadley Center Global Environmental Model, N216 resolution. HG3-N320: Hadley Center Global Environmental Model, N320 resolution. CHIPS: Coupled Hurricane Intensity Prediction System. WRF: Weather Research and Forecasting Model. CAM: Community Atmosphere Model. HadGEM: Hadley Centre Global Environment Model. GFS: Global Forecast System.

\begin{tabular}{|c|c|c|c|}
\hline Center & Model & $\begin{array}{l}\text { Horizontal resolution } \\
\quad(\mathbf{k m} \text { at equator) }\end{array}$ & Experiments run \\
\hline Lawrence Berkeley National Laboratory & CAM5.I & $222,111,25$ & $\begin{array}{l}\text { climo, amip, } 2 \mathrm{CO} 2 \\
2 \mathrm{~K}, 2 \mathrm{~K} 2 \mathrm{CO} 2\end{array}$ \\
\hline $\begin{array}{l}\text { Centro Euro-Mediterraneo sui Cambiamenti } \\
\text { Climatici (CMCC) }\end{array}$ & CMCC-ECHAM5 & 84 & $\begin{array}{l}\text { climo, } 2 \mathrm{CO} 2,2 \mathrm{~K} \\
2 \mathrm{~K} 2 \mathrm{CO} 2\end{array}$ \\
\hline $\begin{array}{l}\text { Centre National de Recherches Météorologiques } \\
\text { (CNRM) }\end{array}$ & CNRM & 50 & amip \\
\hline Florida State University (FSU) & FSU COAPS & 106 & climo, amip, 2CO2, $2 \mathrm{~K}$ \\
\hline $\begin{array}{l}\text { National Oceanic and Atmospheric Administration } \\
\text { Geophysical Fluid Dynamics Laboratory }\end{array}$ & HiRAM & 50 & $\begin{array}{l}\text { climo, amip, } 2 \mathrm{CO} 2 \\
2 \mathrm{~K}, 2 \mathrm{~K} 2 \mathrm{CO} 2\end{array}$ \\
\hline $\begin{array}{l}\text { National Oceanic and Atmospheric Administration } \\
\text { Geophysical Fluid Dynamics Laboratory }\end{array}$ & CI80AM2 & 50 & $\begin{array}{l}\text { climo, } 2 \mathrm{CO} 2,2 \mathrm{~K} \\
2 \mathrm{~K} 2 \mathrm{CO} 2\end{array}$ \\
\hline $\begin{array}{l}\text { NASA Goddard Institute for Space Studies (GISS)- } \\
\text { Columbia University }\end{array}$ & GISS & III & $\begin{array}{l}\text { climo, amip, } 2 \mathrm{CO} 2 \\
2 \mathrm{~K}, 2 \mathrm{~K} 2 \mathrm{CO} 2\end{array}$ \\
\hline NASA Goddard Space Flight Center (GSFC) & GEOS-5 & 56 & $\begin{array}{l}\text { climo, amip, } 2 \mathrm{CO} 2 \\
2 \mathrm{~K}, 2 \mathrm{~K} 2 \mathrm{CO} 2\end{array}$ \\
\hline Hadley Centre & HadGEM3 & 208 & climo, 2K, 2CO2 \\
\hline Hadley Centre & $\mathrm{HG} 3-\mathrm{N} 216$ & 92 & climo, $2 \mathrm{~K}, 2 \mathrm{CO} 2$ \\
\hline Hadley Centre & HG3-N320 & 62 & climo, 2K, $2 \mathrm{CO} 2$ \\
\hline $\begin{array}{l}\text { Japan Agency for Marine-Earth Science and } \\
\text { Technology }\end{array}$ & NICAM & 14 & $\begin{array}{l}\text { Control and } \\
\text { greenhouse runs }\end{array}$ \\
\hline Meteorological Research Institute (MRI) & MRI-AGCM3.IH & 50 & $\begin{array}{l}\text { amip style, } 2 \mathrm{~K}, 2 \mathrm{CO} 2 \text {, } \\
\text { and greenhouse runs }\end{array}$ \\
\hline National Centers for Environmental Prediction & GFS & 106 & $\begin{array}{l}\text { climo, amip, } 2 \mathrm{CO} 2 \\
2 \mathrm{~K}, 2 \mathrm{~K} 2 \mathrm{CO} 2\end{array}$ \\
\hline Texas A\&M University & WRF & 27 & climo, amip, $2 \mathrm{~K} 2 \mathrm{CO} 2$ \\
\hline Massachusetts Institute of Technology & $\begin{array}{c}\text { CHIPS } \\
\text { (downscaling) }\end{array}$ & Variable & $\begin{array}{l}\text { climo, } 2 \mathrm{CO} 2,2 \mathrm{~K} \\
2 \mathrm{~K} 2 \mathrm{CO} 2\end{array}$ \\
\hline
\end{tabular}

the simulation of changes in TC climatology is the ability of climate models [often known as general circulation models (GCMs)] to simulate the current climatology of TCs in the climo HWG experiment or other similar current-climate simulations. In the HWG climo experiment, Fig. 1 shows the simulated global TC numbers range from small values to numbers similar to those observed (Zhao et al. 2013a,b; Shaevitz et al. 2014). Better results can also be obtained from higher-resolution versions of the HWG models (finer than $50-\mathrm{km}$ horizontal resolution), including an ability to generate storms of intense tropical cyclone strength, as shown by Wehner et al. (2014) for a higher-resolution version of the NCAR CAM5 than that shown in Fig. 1. In addition, the tropical cyclone formation rate in the GSFC Goddard
Earth Observing System Model version 5 (GEOS-5) as shown in Fig. 1 has been improved following the development of the new version of the model (see Fig. 4 in Shaevitz et al. 2014).

The annual cycle of formation is reasonably well simulated in many regions, although there is a tendency for the amplitude of the simulated annual cycle to be less than observed. A common factor in many such model assessments is the poorer performance at simulating Atlantic tropical cyclone formation than for other basins, although recent finer-resolution models give an improved simulation. Figure 2 illustrates this point, showing Atlantic results from Mei et al. (2014), from a 25-kmresolution version of the HiRAM, demonstrating the performance of this higher-resolution version of 
the model. Strachan et al. (2013) also found that the observed interhemispheric asymmetry in tropical cyclone formation, with Northern Hemisphere formation rates being roughly twice those in the Southern Hemisphere, was not well captured by a high-resolution GCM.

Why do GCMs generally produce a decrease in future global tropical cyclone numbers? Most GCM future projections indicate a decrease in global tropical cyclone numbers, particularly in the Southern Hemisphere. Knutson et al. (2010) give decreases in the Northern Hemisphere ranging from roughly $0 \%$ to $30 \%$ and in the Southern Hemisphere from $10 \%$ to $40 \%$. Previous explanations of this result have focused

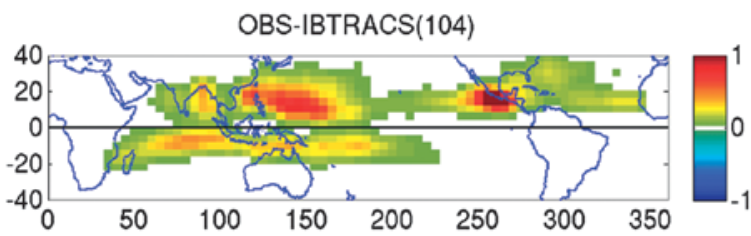

GFDL-HIRAM (total \#:124)

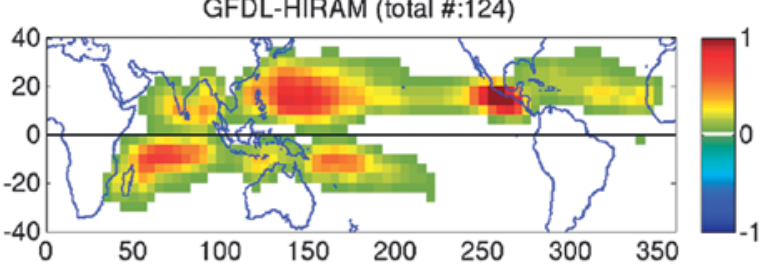

CMCC-ECHAM5 (total \# :72)

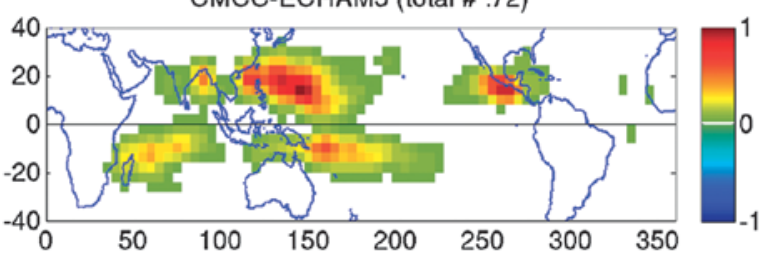

GSFC-GEOS (total \#: 20)

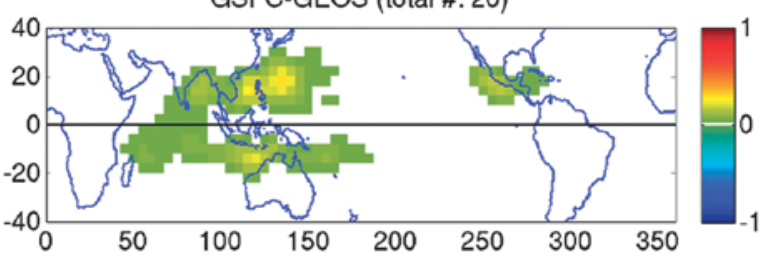

NCAR-CAM5 (total \#: 9)

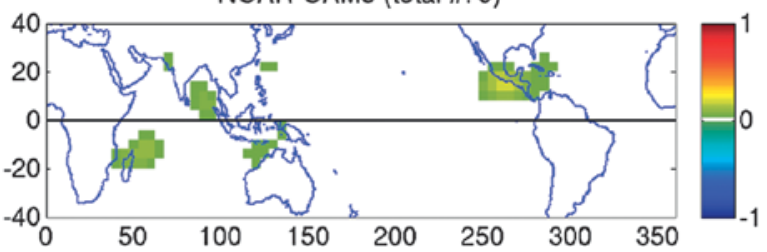

on changes in tropical stability and the associated reduction in climatological upward vertical velocity (Sugi et al. 2002, 2012; Oouchi et al. 2006; Held and Zhao 2011) and on increased midlevel saturation deficits (drying) (e.g., Rappin et al. 2010). In this argument, the tropical cyclone frequency reduction is associated with a decrease in the convective mass flux and an overall related decrease in tropical cyclone numbers. Zhao et al. (2013a,b) compare the HWG model responses for the various simulations, using the Geophysical Fluid Dynamics Laboratory (GFDL) tropical cyclone tracking scheme (Knutson et al. 2008; Zhao et al. 2009). They find that most of the models show decreases in global tropical cyclone frequency for the $2 \mathrm{CO} 2$ run of $0 \%-20 \%$. The changes in TC numbers are most closely related to $500-\mathrm{hPa}$ vertical velocity, with Fig. 3 showing close agreement between changes in tropical cyclone formation and changes in this variable. Here, Fig. $3 b$ shows the annual-mean vertical velocity as an average of monthly-mean vertical velocity weighted by monthly climatological TC genesis frequency over each $4^{\circ} \times 5^{\circ}$ (latitude
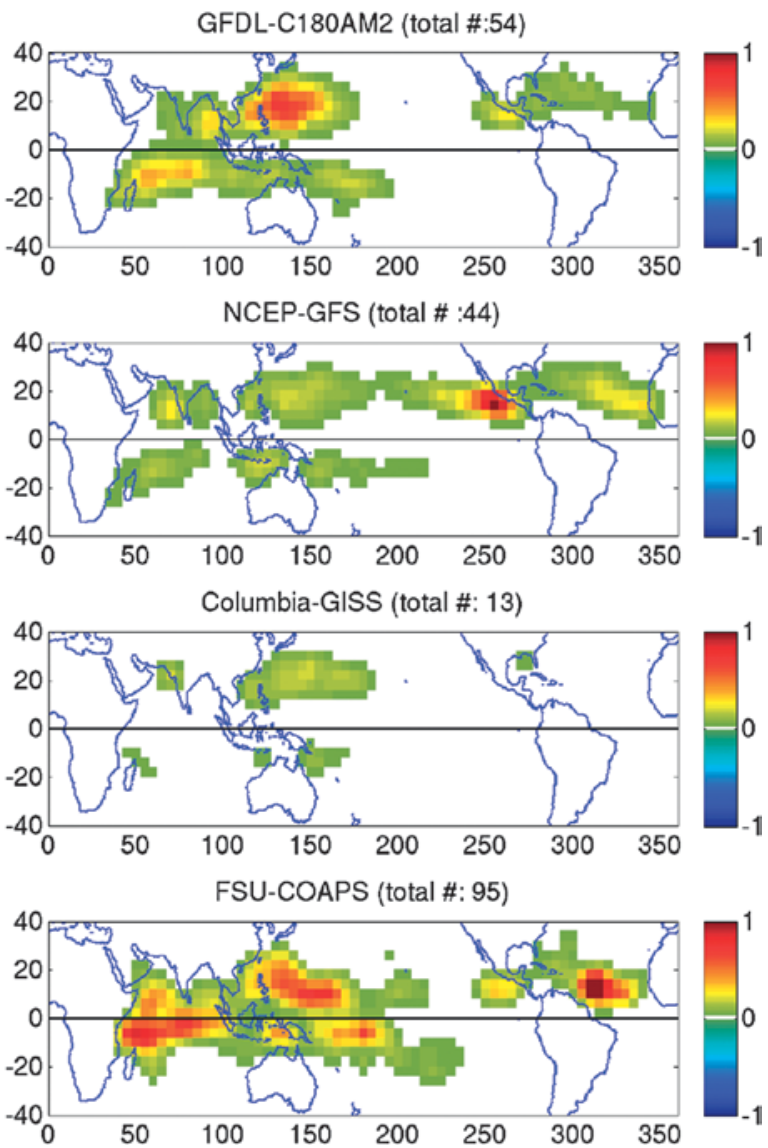

FIG. I. TC formation rates from the International Best Track Archive for Climate Stewardship (IBTrACS) (Knapp et al. 2010) observations and the climo run of the HWG experiments, using the GFDL TC tracking scheme: relative distribution (shaded) and total annual-mean numbers (in panel titles). (From Zhao et al. 20I3a.) 
$\times$ longitude) grid box from the control simulation. This relationship between TC frequency and vertical velocity was the closest association found among a suite of analyzed variables that included precipitation, $600-\mathrm{hPa}$ relative humidity, and vertical wind shear. In addition, Camargo et al. (2014) use a number of GPIs applied to the output of the GFDL HiRAM to show that in order to explain the reduction in TC frequency, it is necessary to include saturation deficit and potential intensity in the genesis potential index. While the response of the models in the other HWG experiments is more ambiguous, no model generated a substantial increase in global TC frequency for any experiment.

The simulated decrease in global tropical cyclone frequency does not appear to be sensitive to the use of a particular parameterization scheme for convection. Murakami et al. (2012a) use a 60-km horizontalresolution version of the MRI atmospheric GCM to demonstrate that patterns of future SST change appear more important in causing future changes in tropical cyclone numbers rather than the choice of the convective parameterization used in their suite of experiments. As the resolution of climate models becomes finer, the need for convective parameterization will become less as microphysical representations of convective processes become more appropriate. Oouchi (2013) has reported simulations of tropical cyclones using a global nonhydrostatic model [Nonhydrostatic Icosahedral Atmospheric Model (NICAM)] run without convective parameterization. It is anticipated that this type of simulation will become increasingly important in the future (e.g., Yamada and Satoh 2013).

The HWG experiments are atmosphere-only climate model experiments and do not include an interactive ocean. In general, however, ocean-atmosphere coupled climate models tend to give similar results to uncoupled atmospheric climate models' results in their response to an imposed greenhouse-induced climate change. Kim et al. (2014), using the GFDL CM2.5 coupled model at a horizontal atmospheric resolution of about $50 \mathrm{~km}$, also note a strong link in their model simulations between decreases in tropical cyclone occurrence and decreases in upward midtropospheric vertical velocity in tropical cyclone formation regions. Like the atmosphere-only models, they also simulate too few storms in the Atlantic. The response to increased $\mathrm{CO}_{2}$ in their model is a substantial decrease in tropical cyclone numbers in almost all basins. Other future changes include a slight increase in storm size, along with an increase in tropical cyclone rainfall. In the coordinated fifth phase of the (a) Observations

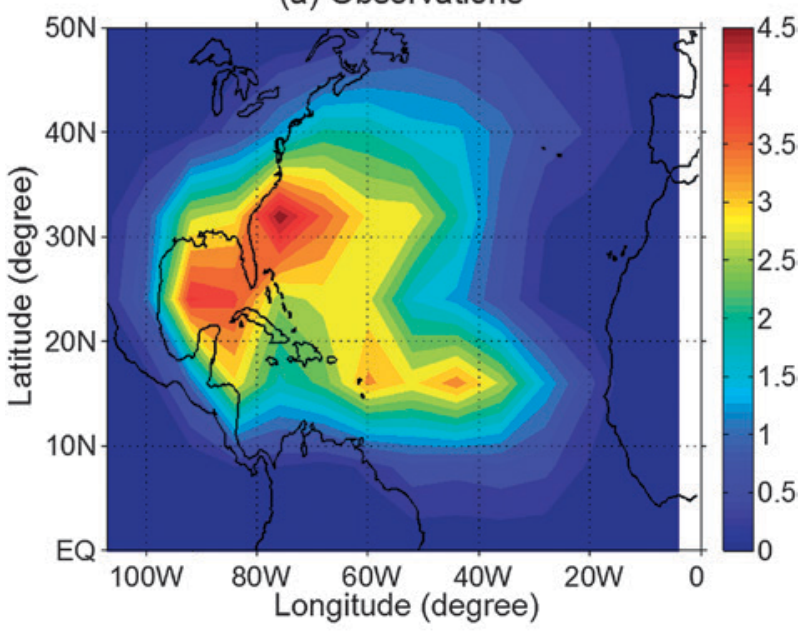

(b) HiRAM

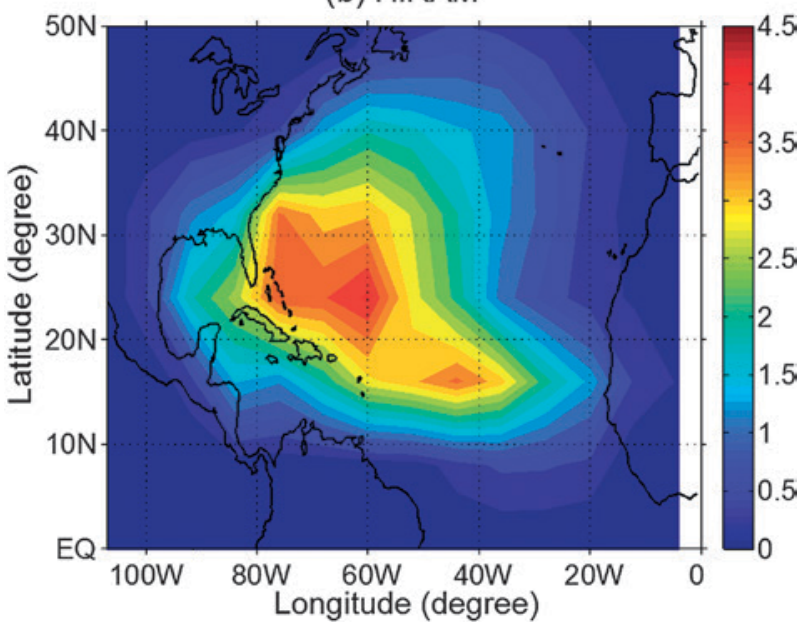

FIG. 2. (a) Observed and (b) simulated geographical distribution of the climatological TC track density (days per year) during the North Atlantic hurricane season calculated for each $8^{\circ} \times 8^{\circ}$ grid element. (From Mei et al. 2014.)

Coupled Model Intercomparison Project (CMIP5; Taylor et al. 2012) coupled ocean-atmosphere model experiments, while there is a significant increase in TC intensity (Maloney et al. 2014), TC frequency changes are not as robust and are dependent on the tracking scheme (Camargo 2013; Tory et al. 2013b; Murakami et al. 2014).

Not all methods for determining TC numbers identify a decrease in future numbers, however. Emanuel $(2013 a, b)$ uses a downscaling method in which incipient tropical vortices are "seeded" into large-scale climate conditions provided from a number of different climate models for current and future climate conditions. The number of "seeds" provided to each set of climate model output is tuned so that the model in question reproduces the observed 
number of tropical cyclones (about 90) in the current climate. This same number of seeds is then provided for the future climate conditions generated by the climate models. In contrast to many models, this system generates more tropical cyclones in a warmer world when forced with the output of climate models running the CMIP5 suite, even when the host CMIP5 model itself produces reduced TC frequency (Camargo 2013; Tory et al. 2013b; Murakami et al. 2014). Analogous results are produced by the same methodology using climate fields from selected HWG model outputs (Fig. 4).

In the HWG experiments, simulated tropical cyclone numbers are most likely to have a small decrease in the $2 \mathrm{~K} 2 \mathrm{CO} 2$ experiment, with a clear majority of models indicating this (Fig. 3). The numbers are also considerably more likely to decrease in the $2 \mathrm{CO} 2$ experiment, but in the $2 \mathrm{~K}$ experiment, there is no genuine preferred direction of future numbers. Overall, the tendency of decreases in tropical cyclone numbers to be closely associated with changes in midtropospheric vertical velocity suggests a strong connection between the two, and one that many other future climate model projections of tropical cyclone numbers also demonstrate. Note that increased saturation deficit, another variable shown to be related to decreases in tropical cyclone

(a)

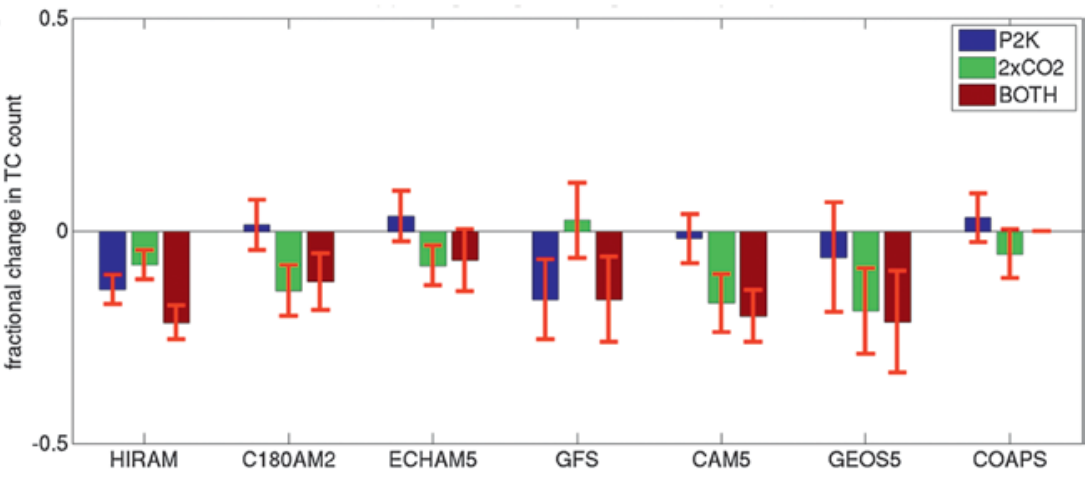

(b)

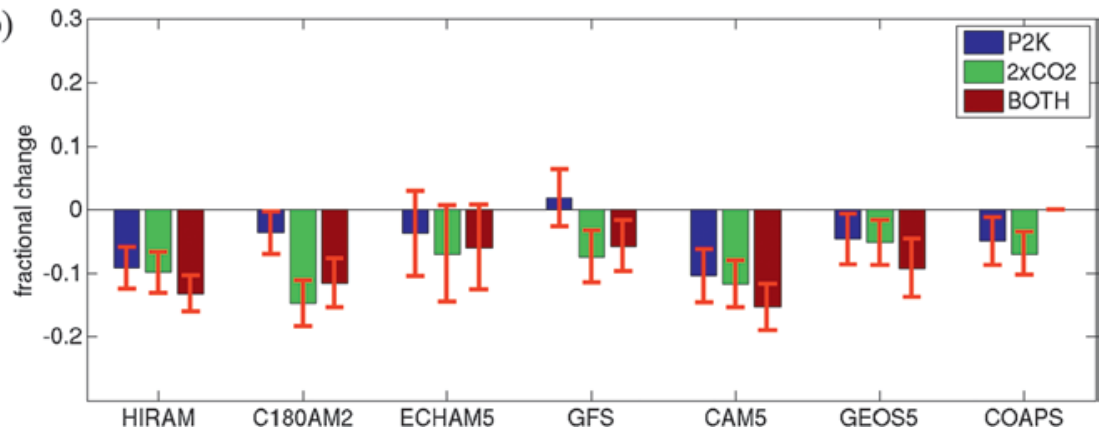

FIG. 3. Comparison between changes in (a) TC formation for various models for the $2 \mathrm{~K}(\mathrm{P} 2 \mathrm{~K})$ and $2 \mathrm{CO} 2$ experiments vs (b) TC genesis as weighted by changes in midtropospheric vertical velocity, as described in the text. (From Zhao et al. 2013a.) numbers, might be expected to accompany a decrease in vertical velocity over the oceans.

Does the new generation of higher-resolution climate models simulate tropical cyclones in the North Atlantic better? Do the models simulate a similar tropical cyclone response to climate change, thus giving more confidence in our prediction? While most models predict fewer tropical cyclones globally in a warmer world, the difference in the model response becomes more significant when smaller regions of the globe are considered. This appears to be a particular issue in the Atlantic basin, where climate model performance has been often poorer than in other formation basins (e.g., Camargo et al. 2005; Walsh et al. 2013b; Camargo 2013; Tory et al. 2013a,b). Since good model performance in simulating the current climate has usually been considered an essential precondition for the skillful simulation of future climate, this poor Atlantic performance poses an issue for the confidence of future tropical cyclone climate in the Atlantic region.

The most recent climate models have begun to simulate this region better, however, most likely due to improved horizontal resolution (Manganello et al. 2012; Strachan et al. 2013; Roberts et al. 2015; Zarzycki and Jablonowski 2014). The best results appear to be achieved at horizontal resolutions finer than $50 \mathrm{~km}$. Roberts et al. (2015) suggest that this may be related to the ability of the higher-resolution models to generate easterly waves with higher values of vorticity than at lower resolution (see also Daloz et al. 2012b). Zhao et al. (2013a) note that more than one of the HWG models produced a reasonable number of tropical cyclones in the Atlantic. Even so, Daloz et al. (2015) showed that the ability of the HWG models to represent the clusters of Atlantic tropical cyclones tracks is inconsistent and varies from model to model, especially for the tracks with genesis over the eastern part of the basin.

Knutson et al. (2013) and Knutson (2013) employ 
the ZETAC regional climate model and global HiRAM, combined with the GFDL hurricane model, to show that in addition to simulating well the present-day climatology of tropical cyclone formation in the Atlantic, they are also able to simulate a reasonably realistic distribution of tropical cyclone intensity. Manganello et al. (2012) showed a similar ability in a high-resolution GCM (see below for more on intensity). These simulations mostly show a decrease in future numbers of Atlantic storms.

Substantial increases in observed Atlantic tropical cyclone numbers have already occurred in the past 20 years, likely driven by changes in the Atlantic meridional mode (AMM; Servain et al. 1999; Vimont and Kossin 2007; Kossin et al.2010) on decadal time scales and the Atlantic multidecadal oscillation (AMO; Delworth and Mann 2000) on multidecadal time scales. A number of detailed explanations of changes in TC numbers related to these climate variations have been suggested, ranging from changes in upper-tropospheric temperatures (Emanuel et al. 2013; Vecchi et al. 2013) to the "relative SST" argument of Vecchi and Soden (2007), namely, that increases in TC numbers are related to whether local SSTs are increasing faster than the tropical average. Changes in tropospheric aerosols have also been implicated (Villarini and Vecchi 2012). Camargo et al. (2013) and Ting et al. $(2013,2015)$ show that the effect of Atlantic SST increases alone on Atlantic basin potential intensity is considerably greater than the effect on Atlantic basin PI of global SST changes. Figure 5 shows that regression coefficients that indicate the strength of this relationship are considerably larger for SSTs forced by the AMO (left panels) than for the global climate change signal (right panels), for a range of both current-climate and future-climate simulations. This suggests that increases in local PI are likely related to whether the local SST is increasing faster than the global average. Ting et al. (2015) show that by the end of this century, the change in PI due to climate change should dominate the decadal variability signal in the Atlantic but that this climate change signal is not necessarily well predicted by the amplitude in the relative SST signal. Knutson (2013) finds that relative SST appears to explain the predicted evolution of future Atlantic TC numbers reasonably well (see also Villarini et al. 2011).

The issue of the relative importance of large-scale climate variations for tropical cyclone formation in the Atlantic region is related to the ability of dynamical seasonal forecasting systems to predict year-to-year tropical cyclone numbers in the Atlantic. In general, despite the challenges of simulating tropical cyclone climatology in this basin, such models have good skill in this region (LaRow et al. 2014; Schemm and Long 2013; Saravanan et al. 2013). This skill is clearly assisted by models being well able to simulate the observed interannual variability of tropical cyclone formation in this region, as shown by Emanuel et al. (2008), LaRow et al. (2008), Knutson et al. (2007), Zhao et al. (2009), LaRow et al. (2014), Knutson (2013), Patricola et al. (2014), Roberts et al. (2015), and Wang et al. (2014b). This suggests that tropical cyclone formation in the Atlantic basin is highly related to the climate variability of the environmental variables in the basin rather than to the stochastic variability of the generation of precursor disturbances in the basin. This also suggests that provided the challenge of simulating the tropical cyclone climatology in this region can be overcome, and provided that the relative contributions of the existing substantial decadal variability and the climate change signal can be well quantified, simulations in this basin may achieve more accurate predictions of the effect of climate change on tropical cyclone numbers. 
While the Atlantic basin has been a particular focus of this work, the basin with the greatest annual number of tropical cyclones is the northwest Pacific. The HWG simulations mostly show decreases in numbers in this basin for the $2 \mathrm{~K} 2 \mathrm{CO} 2$ experiment. This is in general agreement with results from previous model simulations of the effect of anthropogenic warming on tropical cyclone numbers. Some recent results for predictions in other regions of the globe suggest some consensus among model predictions. For instance, $\mathrm{Li}$ et al. (2010), Murakami et al. (2013), Murakami et al. (2014), Kim et al. (2014), and Roberts et al. (2015) suggest that the region near Hawaii may experience an increase in future tropical cyclone numbers. Walsh et al. (2013a,b) and Zhao et al. (2013a,b) indicate that HWG and other model projections tend to produce more consistent decreases in TC numbers in the Southern Hemisphere than in the Northern Hemisphere. The cause of this interhemispheric inhomogeneity is currently uncertain, but it is speculated that it is due to fundamental differences caused by the land-sea distribution in the two hemispheres.

What is the tropical cyclone response of climate models to an imposed, common increase in SST? How sensitive is the simulation of tropical cyclone variability to differences in SST analysis? Previous work has shown that tropical cyclone numbers decrease in response
AMO Reg. Hist. Multi-model Mean

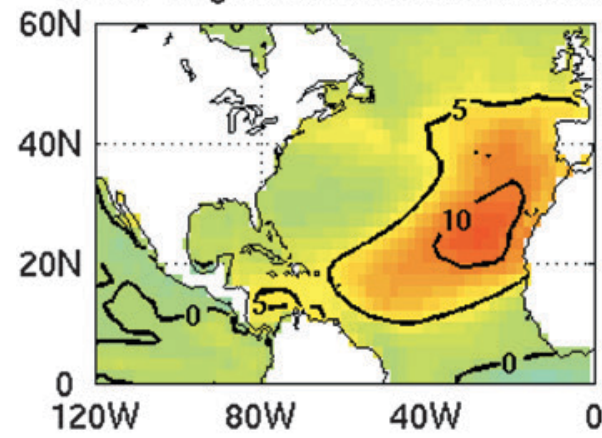

AMO Reg. rcp4.5 Multi-model Mean
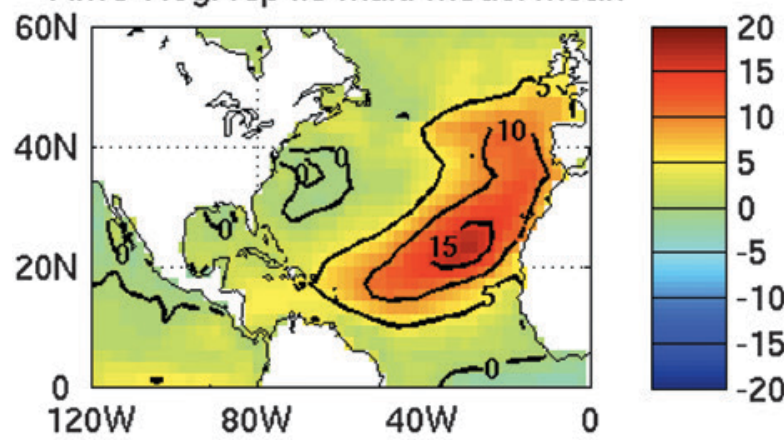

AMO Reg. rcp8.5 Multi-model Mean

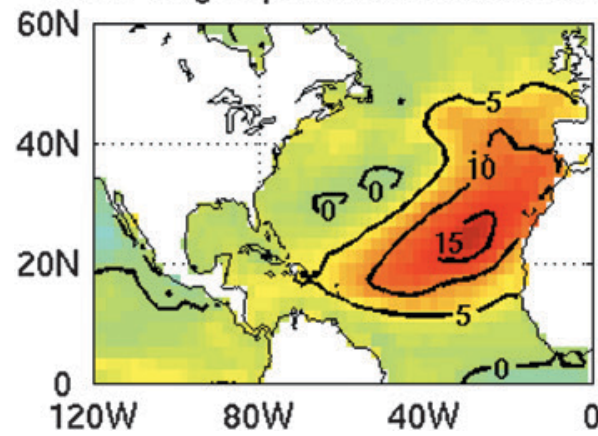

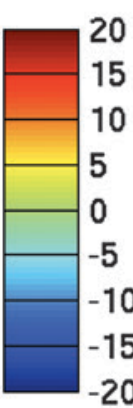

$-20$

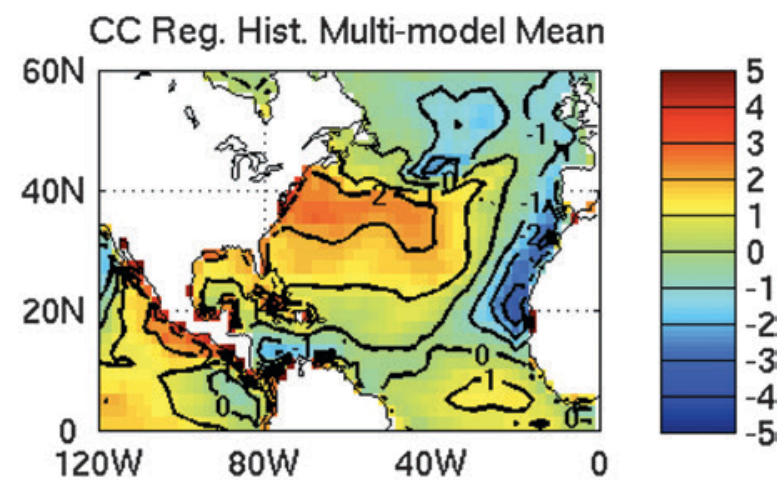

CC Reg. rcp4.5 Multi-model Mean

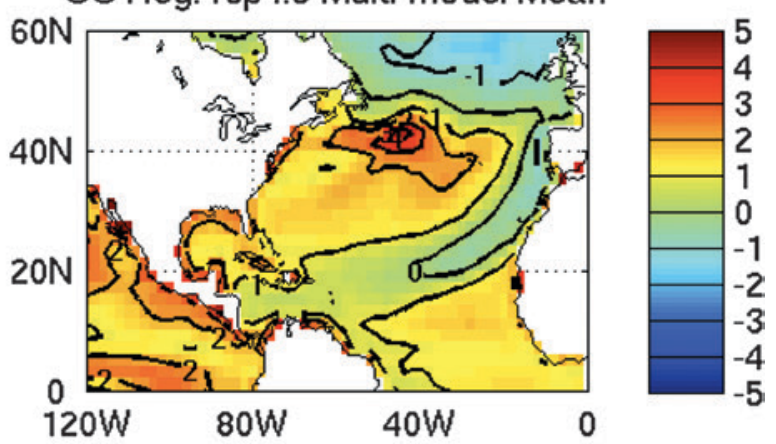

CC Reg. rcp8.5 Multi-model Mean

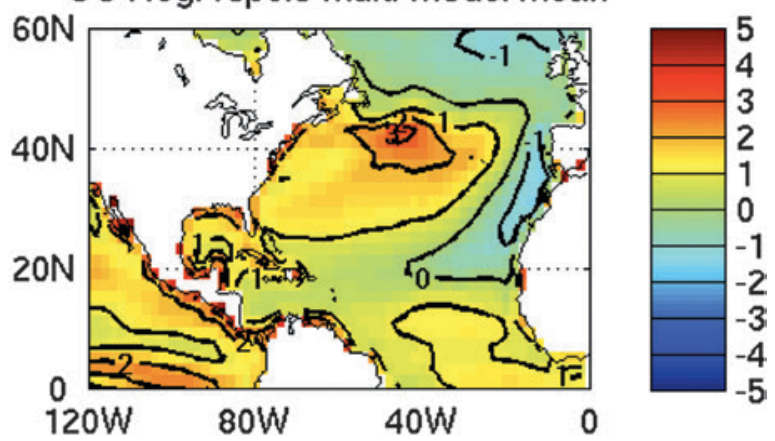

FIG. 5. (left) Regression of PI on AMO and (right) climate change signals for the CMIP5 multimodel ensemble, for historical and two future climate simulations using the rcp4.5 and rcp8.5 greenhouse gas emissions scenarios (van Vuuren et al. 20II). Units are $\mathrm{m} \mathrm{s}^{-1} \mathrm{~K}^{-1}$ of SST index (AMO or CMIP5). (From Ting et al. 20I5.) 
to the imposition of a uniform ocean warming (Yoshimura and Sugi 2005; Held and Zhao 2011). The relevant experiment here is the $2 \mathrm{~K}$ experiment of the HWG modeling suite. In general, of those HWG models that generate a substantial number of tropical cyclones, slightly more models show global numbers that decrease rather than increase, although the difference is not large.

Some insight has been previously provided into the issue of the sensitivity of GCM results to the specification of the forcing SST dataset. Po-Chedley and Fu (2012) conduct an analysis of the CMIP5 AMIP simulations, and it is noted that the HWG models participating in the CMIP5 AMIP experiments used a different SST dataset (HadISST; Rayner et al. 2003; the one used for the HWG experiments) than the one recommended for the CMIP5 AMIP experiments (the "Reynolds" dataset; Reynolds et al. 2002). These HWG models have a weaker and more realistic upper-tropospheric warming over the historical period of the AMIP runs, suggesting that there is some sensitivity to the specification of the SST datasets. This difference in SST datasets could conceivably have an effect on tropical cyclones in these models, through changes in either formation rates due to changes in stability or through changes in intensity caused by effects on PI. This issue remains unresolved at present.

How does the role of changes in atmospheric carbon dioxide differ from the role played by SSTs in changing tropical cyclone characteristics in a warmer world? The HWG experiments indicate that it was more likely for tropical cyclone numbers to decrease in the $2 \mathrm{CO} 2$ experiments than in the $2 \mathrm{~K}$ experiments (Fig. 3a). Zhao et al. (2013a,b) show that, for several of the HWG models, decreases in midtropospheric vertical velocity are generally larger for the $2 \mathrm{CO} 2$ experiments than for the $2 \mathrm{~K}$ experiments (Fig. $3 \mathrm{~b}$ ). For the $2 \mathrm{CO} 2$ experiment, the decrease in upward mass flux has previously been explained by Sugi and Yoshimura (2004) as being related to a decrease in precipitation caused by the decrease in radiative cooling aloft. This is caused by the overlap of $\mathrm{CO}_{2}$ and water vapor absorption bands, whereby an increase in $\mathrm{CO}_{2}$ will reduce the dominant radiative cooling due to water vapor. This argument assumes that tropical precipitation rates are controlled by a balance between convective heating and radiative cooling (Allen and Ingram 2002). The simulated decrease in precipitation was combined with little change in stability. In contrast, in their $2 \mathrm{~K}$ experiment, precipitation increased but static stability also increased, which was attributed to a substantial increase in uppertroposphere temperature due to increased convective heating. Yoshimura and Sugi (2005) note that these effects counteract each other and may lead to little change in the upward mass flux, thus leading to little change in tropical cyclone formation rates for the $2 \mathrm{~K}$ experiment, as seen in their results. A thorough analysis of the HWG experiments along these lines has yet to be performed, however.

The $2 \mathrm{~K}$ and $2 \mathrm{CO} 2$ experiments may also have different effects on the intensity of storms. If fineresolution models are used, then it is possible to simulate reasonably well the observed distribution of intensity (see below). The model resolutions of the HWG experiments are in general too coarse to produce a very realistic simulation of the observed tropical cyclone intensity distribution. Nevertheless, some insight into the overall effects of these forcings on the intensity of storms can be obtained, particularly when compared with the almost resolution-independent PI theory. First, Held and Zhao (2011) showed that one of the largest differences between the results of the $2 \mathrm{~K}$ and $2 \mathrm{CO} 2$ experiments conducted for that paper was that PI increased in the $2 \mathrm{~K}$ experiments but decreased in the $2 \mathrm{CO} 2$ experiment, owing to the relative changes in surface and upper-tropospheric temperatures in the two cases. In addition, directly simulated intense tropical cyclone (hurricane) numbers decrease more as a fraction of their total numbers in the $2 \mathrm{CO} 2$ experiment than they did in the $2 \mathrm{~K}$ experiment, consistent with the PI results. A similar behavior is seen in the HWG experiments, although apart from the HiRAM results, there is a general suppression of storms across all intensity categories rather than a preferential suppression of hurricane-intensity storms (Zhao et al. 2013a). In contrast, previous model simulations at higher resolutions than employed for the HWG experiments have tended to indicate an increase in the number of more intense storms (e.g., Knutson et al. 2010).

How does air-sea interaction modify the climate response of tropical cyclones? If the SST field from a coupled ocean-atmosphere model run is applied as the lower boundary condition for a specified-SST "time slice" AGCM run, then it has been shown previously that the resulting atmospheric climate differs from the original atmospheric climate of the corresponding coupled ocean-atmosphere model run (Timbal et al. 1997). Thus, the presence of airsea interaction itself appears to be important for the generation of a particular climate. 
This issue is not addressed directly through the design of the HWG experiments. Emanuel and Sobel (2013) show by an analysis of thermodynamic parameters associated with tropical cyclone intensity that SST should not be considered a control variable for tropical cyclone intensity on time scales longer than about two years; rather, it is a quantity that tends to covary with the same control variables (surface wind, surface radiative fluxes, and ocean lateral heat fluxes) that control potential intensity. Thus, it can be argued that simulations that used specified SSTs risk making large errors in potential intensity, related to their lack of surface energy balance. Nevertheless, Kim et al. (2014) use the GFDL coupled model running at a resolution of $50 \mathrm{~km}$ to show that the inclusion of coupling does not necessarily change the direction of the tropical cyclone frequency response. As a result, these runs also show decreases in the global number of tropical cyclones and also undersimulate currentclimate numbers in the Atlantic. It is noted that this might be due to a cold bias in the SST simulation in the Atlantic. Daloz et al. (2012a), using a stretched configuration of CNRM-CM5 with a resolution of up to $60 \mathrm{~km}$ over the Atlantic, also showed an underestimate of tropical cyclone activity when coupling was introduced.

Are the results sensitive to the choice of cyclone tracking scheme? An essential first step in the analysis of any tropical cyclone detection scheme is to select a method for detecting and tracking the storms in the model output. A number of such schemes have been developed over the years; they share many common characteristics but also have some important differences. They fall into five main categories, although some schemes contain elements of more than one category:

1) structure-based threshold schemes, whereby thresholds of various structural parameters are set based on independent information, and storms detected with parameter values above these thresholds are declared to be tropical cyclones (e.g., Walsh et al. 2007);

2) variable threshold schemes, in which the thresholds are set so that the global number of storms generated by the model is equal to the currentclimate observed annual mean (e.g., Murakami et al. 2011);

3) schemes in which model output is first interpolated onto a common grid before tracking (e.g., the feature tracking scheme of Hodges 1995; Bengtsson et al. 2007a; Strachan et al. 2013);
4) model-threshold-dependent schemes, in which the detection thresholds are adjusted statistically, depending upon the formation rate in a particular model, originally developed for seasonal forecasting with basin-dependent thresholds (e.g., Camargo and Zebiak 2002); and

5) circulation-based schemes, in which regions of closed circulations and enhanced vorticity with low deformation are identified based on the Okubo-Weiss-Zeta diagnostic (Tory et al. 2013a).

It is possible to make arguments for and against each type of scheme, but clearly the change in tropical cyclone numbers of the climate model simulations should not be highly dependent on the tracking scheme used, and if the direction of the predicted change is sensitive to this, this would imply that the choice of the tracking scheme is another source of uncertainty in the analysis. To examine this issue, results from the HWG simulations are compared for different tracking schemes. In general, after the correction is made for differences in user-defined thresholds between the schemes, there is much more agreement than disagreement on the sign of the model response between different tracking schemes (Horn et al. 2014; Fig. 6). Nevertheless, it is possible to obtain a different sign of the response for the same experiment by using a different tracking scheme. In the case of CMIP5 models, changes in TC frequency in future climates was clearly dependent on the tracking routine used, especially for the models with poor TC climatology (see Camargo 2013; Tory et al. 2013b; Murakami et al. 2014). This could simply be a sampling issue caused by insufficient storm numbers in the various intensity categories rather than any fundamental difference between the model responses as estimated by the different tracking schemes or the effect of user-specific threshold detection criteria. This may still imply that results from such simulations should be examined using more than one tracking scheme.

Climatological controls on formation. It has been recognized for some time that one consequence of a warmer climate is an increase in the typical threshold of the initiation of deep convection, a precursor of tropical cyclone formation (Dutton et al. 2000; Evans and Waters 2012; Evans 2013). This threshold varies within the current climate as well (Evans 2013). The search for relevant diagnostics of tropical cyclone formation that can be derived from the mean climate has led to the formulation of GPI parameters that statistically relate tropical cyclone formation to 
climatological mean values of parameters that are known to influence tropical cyclone formation (Gray 1979; Royer et al. 1998; Emanuel and Nolan 2004; Emanuel 2010; Tippett et al. 2011; Bruyère et al. 2012; Menkes et al. 2012; Korty et al. 2012a,b). GPIs usually include values of atmospheric variables such as vertical wind shear, PI, midtropospheric relative humidity, and SST. Another large-scale environmental factor that should be considered is the ventilation, the import of cooler and drier air, which was shown to have an important influence in both tropical cyclogenesis and intensification (Tang and Emanuel 2012). Changes in TC frequency in future climates have also been related to the ventilation index for the CMIP5 models (Tang and Camargo 2014).

The potential of such a technique is obvious: it could serve as a diagnostic tool to determine the reasons for changes in tropical cyclone numbers in a particular climate simulation, without the need to perform numerous sensitivity experiments, or (ultimately) it could enable the diagnosis of changes in tropical cyclone formation rate from different climates without the need to run a high-resolution GCM to simulate the storms directly, similar to what was done in the present climate for diagnostics of TC genesis modulation by El Niño-Southern Oscillation (Camargo et al. 2007a) and the MaddenJulian oscillation (Camargo et al. 2009). Korty et al. $(2013,2012 a, b)$ show results where the GPI is used to diagnose the rate of tropical cyclone formation for a period 6,000 years before the present, showing considerable changes in GPI, with mostly decreases in the Northern Hemisphere and increases in the Southern Hemisphere. It is noted, however, that while GPIs appear to have some skill in estimating the observed spatial and temporal variations in the number of tropical cyclones (Menkes et al. 2012), there are still important discrepancies between their estimates and observations. In addition, there can be similar differences between GPI estimates and directly simulated tropical cyclone numbers, which appear to be better in models with higher resolution (Camargo et al. 2007b; Walsh et al. 2013b; Camargo 2013). A potential limitation of the GPI methodology for application to a different climate is that it is trained on presentday climate. This was demonstrated in the $25-\mathrm{km}$ version of the CAM5 GCM, where decreases in GPI estimated for the 2CO2 experiment were consistent with the direct simulation but increases in GPI estimated for the $2 \mathrm{~K}$ and $2 \mathrm{~K} 2 \mathrm{CO} 2$ experiments were inconsistent with the direct simulation of changes in tropical cyclone numbers (Wehner et al. 2015; see also Camargo 2013; Camargo et al. 2014). (a)

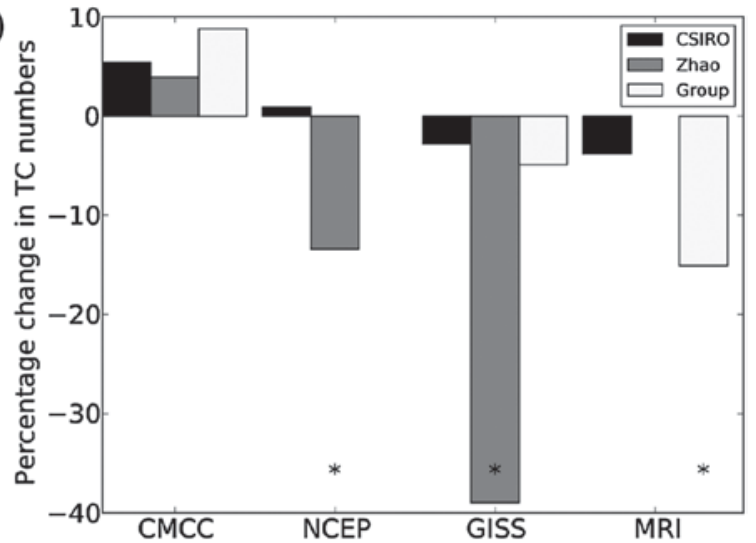

(b)

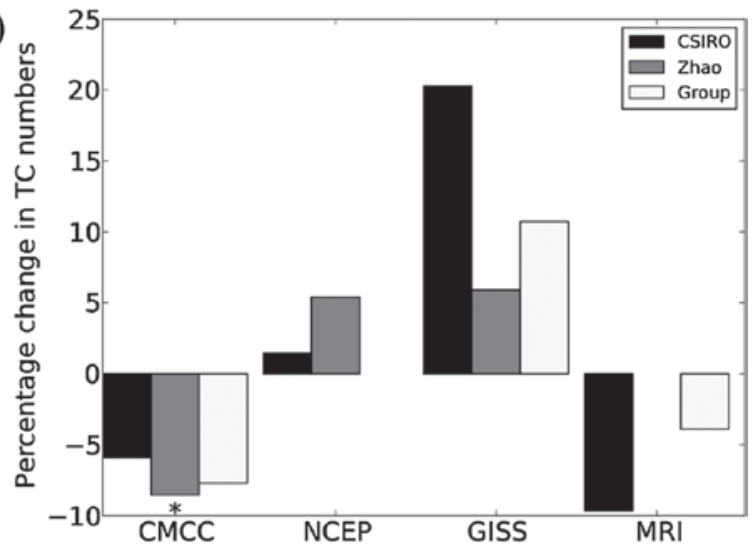

(c)

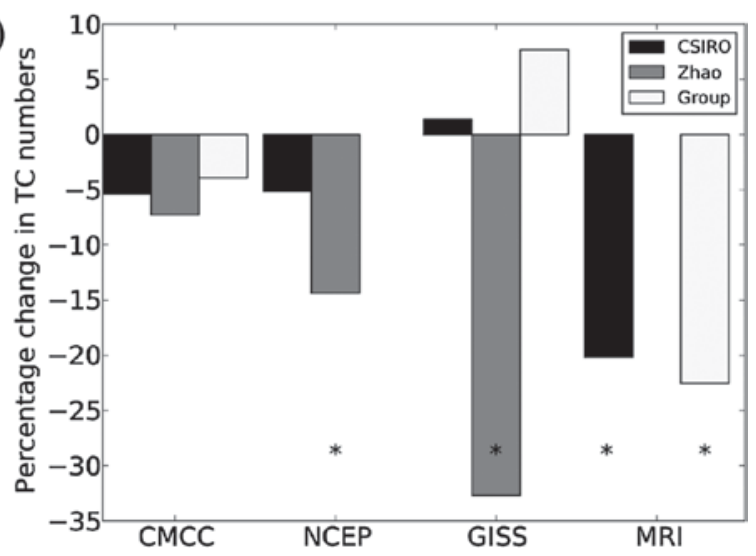

Fig. 6. Percentage change in TC numbers in each model for the three altered climate experiments relative to the present-day experiment, as tracked by the Commonwealth Scientific and Industrial Research Organisation (CSIRO), Zhao, and individual group tracking schemes, after homogenization in (a) duration, (b) wind speed, and (c) latitude of formation. Asterisks indicate statistical significance to at least the $p=0.05$ level.

The role of idealized simulations in understanding the influence of climate on tropical cyclones is highlighted by Merlis et al. (2013). A series of idealized experiments with land areas removed 
(so-called aquaplanet simulations) show that the position of the intertropical convergence zone (ITCZ) is crucial for the rate of generation of tropical cyclones. If the position of the ITCZ is not changed, then a warmer climate leads to a decrease in tropical cyclone numbers, but a poleward shift in the ITCZ leads to an increase in tropical cyclone numbers. With a new generation of climate models being better able to simulate tropical cyclone characteristics, there appears to be an increased scope for using models to understand fundamental aspects of the relationship between climate and tropical cyclones.

Sensitivity of results to choice of convection scheme. Murakami et al. (2012a) show experiments investigating the sensitivity of the response of TCs to future warming using time slice experiments. Decreases in future numbers of tropical cyclones are shown for all experiments irrespective of the choice of convection scheme. Note that there also appears to be considerable sensitivity of tropical cyclone formation to the specification of the minimum entrainment rate (Lim et al. 2015). As this is decreased (equivalent to turning off the cumulus parameterization), the number of tropical cyclones increases. The sensitivity of the TC frequency

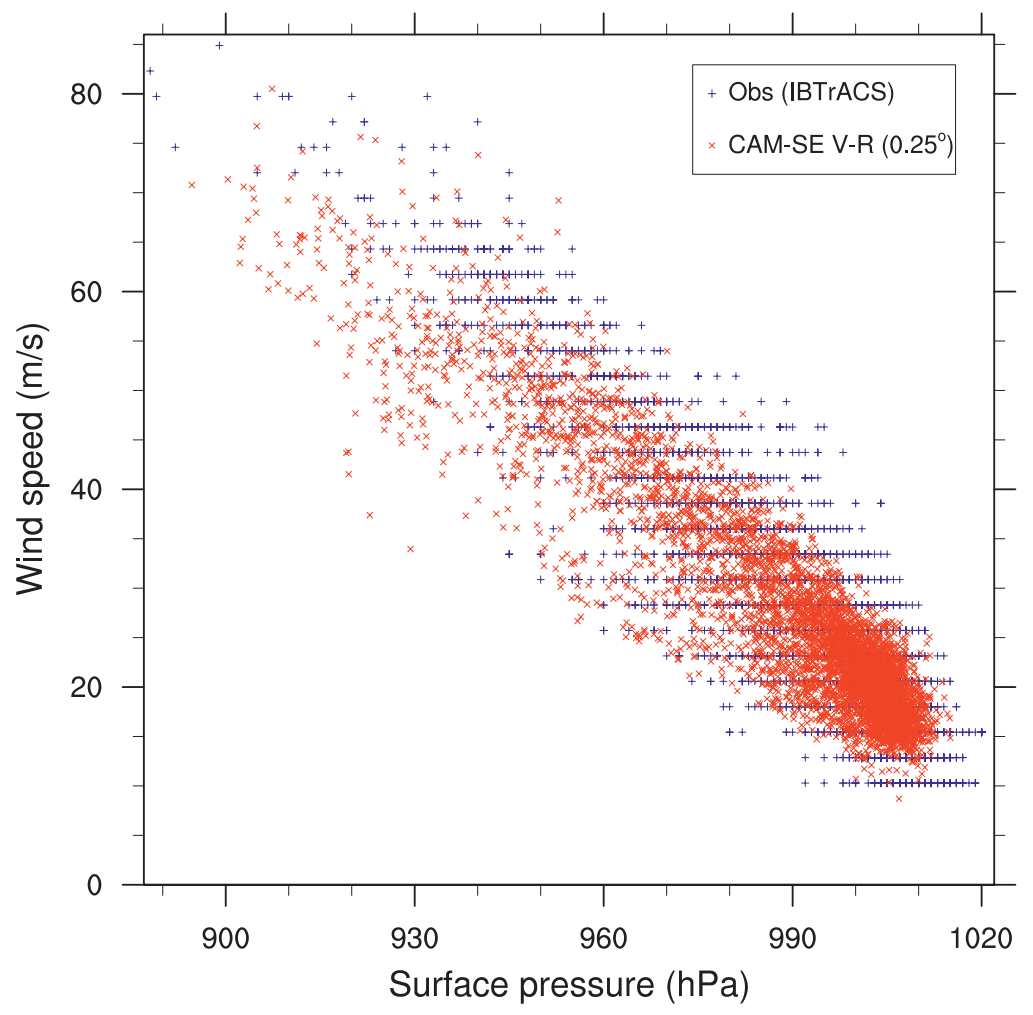

FIG. 7. Comparison between North Atlantic observed (blue) and simulated (red) wind-pressure relationships during the 1980-2002 period for the high-resolution $\left(0.25^{\circ}\right)$ CAM-SE model, for central TC pressure and I0-m wind speed. (From Zarzycki and Jablonowski 2014.) to other convection scheme parameters (fractional entrainment rate and rate of rain reevaporation) was also shown in Kim et al. (2012) with the GISS model, with a larger entrainment rate causing fewer TCs but an increase in rain reevaporation substantially increasing TC numbers. One issue that needs to be examined is that an increase in tropical storm numbers due to changes in the convective scheme to more realistic values is not necessarily accompanied by an improvement in the simulation of the mean climate state. A similar issue occurs in the simulation of the intraseasonal variability in climate models, where there is a systematic relationship between the amplitude of the intraseasonal variability in the models and mean state biases in climate simulations (Kim et al. 2011).

\section{TROPICAL CYCLONE INTENSITY. Work in} the past couple of decades has led to the generally accepted theory that the potential intensity of tropical cyclones can be quantified by thermodynamic arguments (Emanuel 1986; Emanuel 1988; Holland 1997; see also Knutson et al. 2010). While the focus of the HWG has been on numerical model simulation, the use of theoretical diagnostics such PI has been an important part of efforts to understand the results produced by the models.

Emanuel and Sobel (2013, 2014) outline some of the important unresolved theoretical issues related to maximum tropical cyclone intensity, including the physics of air-sea interaction at very high wind speeds, the existence and magnitude of supergradient winds in the hurricane boundary layer, horizontal mixing by eddies, and the radial structure and characteristics of the outflow temperature (see also Wang et al. 2014b; Ramsay 2013). In addition, most tropical cyclones do not reach their maximum intensities (Wing et al. 2007; Kossin and Camargo 2009), and while factors that inhibit their intensification are well known (e.g., vertical wind shear, dry midtropospheric air, and land surfaces), less certain is the precise quantitative response of tropical cyclones to changes in these quantities. Ideally, there should be a strong correspondence between the theoretical PI and the simulated maximum intensity of 
storms in a model climatology of tropical cyclones.

Simulation of the intensity distribution of tropical cyclones. While it is clear that simply increasing the resolution does not necessarily improve intensity distribution (Shaevitz et al. 2014), results from the HWG simulations indicate that a very significant improvement in a GCM's ability to simulate both TC formation and intensity occurs at resolutions finer than $50 \mathrm{~km}$, with good results shown at $25 \mathrm{~km}$ (Strachan et al. 2013; Roberts et al. 2015; Lim et al. 2015; Wehner et al. 2015; Mei et al. 2014). In addition, if such high resolution is employed, it is possible to simulate reasonably well the observed intensity distribution of tropical cyclones (Bender et al. 2010; Lavender and

Walsh 2011; Murakami et al. 2012b; Knutson 2013; Chen et al. 2013; Zarzycki and Jablonowski 2014). Figure 7 illustrates this for the $25-\mathrm{km}$ version of the CAM with the Spectral Element (CAM-SE), with typical simulated wind speeds (red crosses) for intense storms being only slightly lower for the same central pressure than in the observations (blue crosses). This is due to the model at this resolution not being quite able to simulate pressure gradients that are as large as those observed. Nevertheless, Manganello et al. (2012) showed that there remained some discrepancies in the wind pressure relationship between observations and even very high-horizontalresolution $(10 \mathrm{~km})$ simulations.

OTHER ISSUES. Future TC precipitation. Previous work has shown a robust signal of increasing amounts of precipitation per storm in a warmer world (Knutson and Tuleya 2004; Manganello et al. 2012; Knutson 2013; Kim et al. 2014; Roberts et al. 2015). The size of this signal varies a little between simulations, from approximately $10 \%$ to $30 \%$. Knutson (2013) shows that this increase in precipitation close to the center of the storm appears to be greater than the Clausius-Clapeyron rate of 7\% per degree of warming owing to the additional source of moisture supplied by the secondary circulation (inflow) of the tropical cyclone.

Villarini et al. (2014) and Scoccimarro et al. (2014) have investigated the response of precipitation from landfalling tropical cyclones in the HWG experiments (Fig. 8). Scoccimarro et al. (2014) find that compared to the present-day simulation, there is an increase in TC precipitation for the scenarios involving SST increases. For the $2 \mathrm{CO} 2$ run, the changes in TC rainfall are small and it was found that, on average, TC rainfall for that experiment tends to decrease compared to the present-day climate. The results of Villarini et al. (2014) also indicate a reduction in TC daily precipitation rates in the $2 \mathrm{CO} 2$ scenario, of the order of $5 \%$ globally, and an increase in TC rainfall rates when SST is increased, both in the $2 \mathrm{~K}$ and $2 \mathrm{~K} 2 \mathrm{CO} 2$ runs, about $10 \%-20 \%$ globally. The authors propose an explanation of the decrease in precipitation in the $2 \mathrm{CO} 2$ runs is similar to that described by Sugi and Yoshimura (2004) above, while 
the increases in the $2 \mathrm{~K}$ runs are a result of increased surface evaporation. A number of issues are identified for future work, including the need to stratify the rainfall rate by intensity categories and an examination of the extratropical rainfall of former TCs.

Novel analysis techniques. Strazzo et al. (2013a,b) present results in which a hexagonal regridding of the model output variables and tracks enable some analysis of their interrelationships to be performed efficiently. Once this is done for the HWG experiments, it is noted that one can define a "limiting intensity" that is the asymptotic intensity for high return periods. The sensitivity of this limiting intensity to SST is lower in the models than in the observations, perhaps a reflection of the lack of high-intensity storms in most HWG model simulations. This technique can also be used to establish performance metrics for the model output in a way that can be easily analyzed statistically.

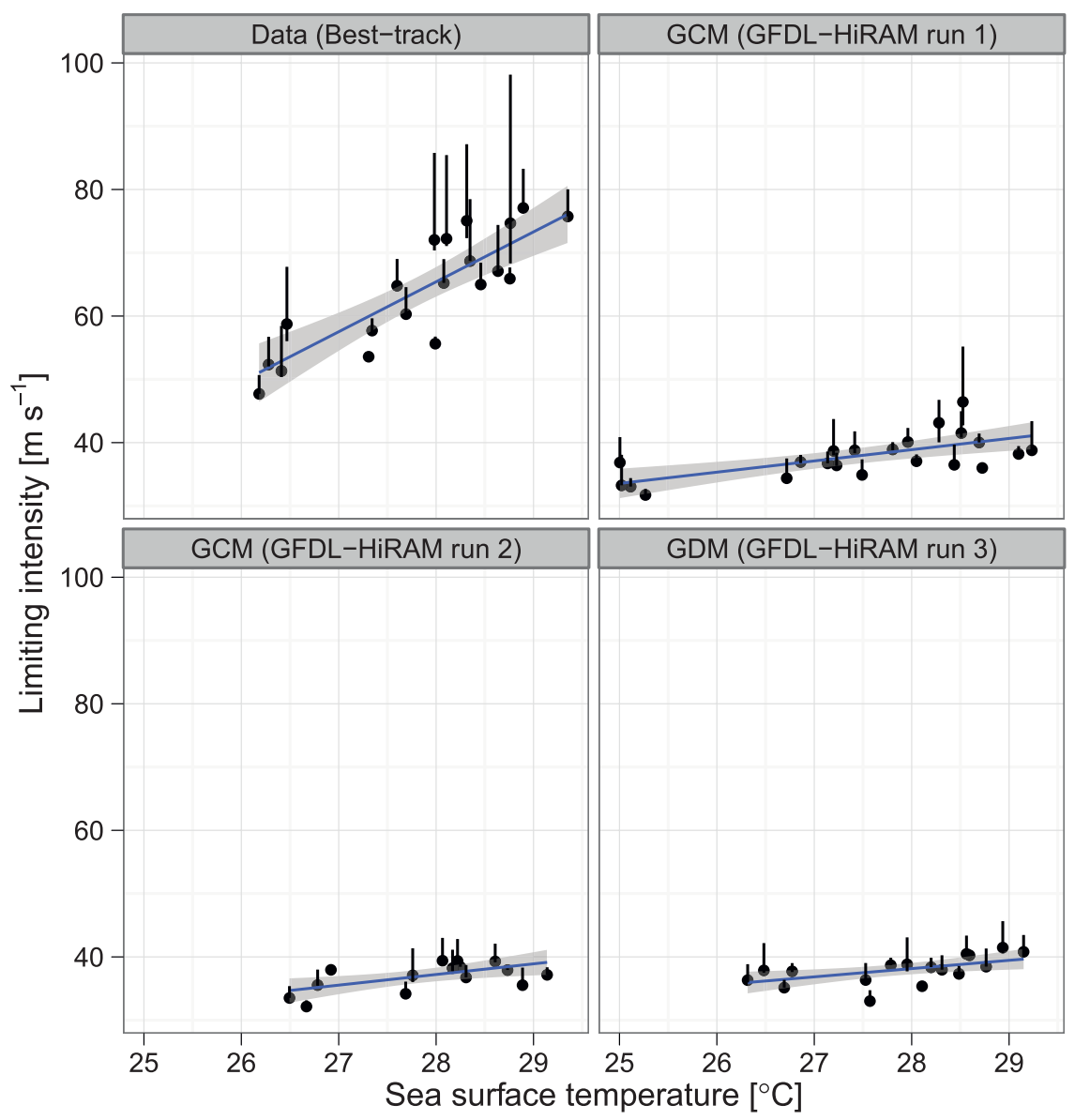

FIG. 9. Sensitivity of limiting intensity to SST $\left(\mathrm{m} \mathrm{s}^{-1}{ }^{\circ} \mathrm{C}^{-1}\right)$ for (top left) observed TCs and three runs of the GFDL HiRAM, indicated by the slope of the blue line. Gray shading represents the $95 \%$ confidence interval, while the vertical black bars depict uncertainty, obtained through a bootstrapping technique, about the limiting intensity estimates.
Strazzo et al. (2013a,b) and Elsner et al. (2013) use this novel analysis technique to show that the sensitivity of limiting intensity to SST is $8 \mathrm{~m} \mathrm{~s}^{-1} \mathrm{~K}^{-1}$ in observations and about $2 \mathrm{~m} \mathrm{~s}^{-1} \mathrm{~K}^{-1}$ in the HiRAM and Florida State University (FSU) models (Fig. 9). They speculate that the lower sensitivity is due to the inability of the model-derived TCs to operate as idealized heat engines, likely due to unresolved innercore thermodynamics that then limit the positive feedback process between convection and surface heat fluxes, which is responsible for TC intensification. They further speculate that GCM temperatures near the tropopause do not match those in the real atmosphere, which would likely influence the sensitivity estimates.

\section{GAPS IN OUR UNDERSTANDING AND}

FUTURE WORK. In summary, the HWG experiments have shown systematic differences between experiments in which only sea surface temperature is increased versus experiments where only atmospheric carbon dioxide is increased, with the carbon dioxide experiments more likely to demonstrate the decrease in tropical cyclone numbers previously shown to be a common response of climate models in a warmer climate. Experiments where the two effects are combined also show decreases in numbers, but these tend to be less for those models that demonstrate a strong tropical cyclone response to increase sea surface temperatures. Analysis of the results has established firmer links between tropical cyclone formation rates and climate variables such as midtropospheric vertical velocity, with decreased climatological vertical velocities leading to decreased tropical cyclone formation. Some sensitivity in the experimental results has been shown to the tropical cyclone detection 
and tracking scheme chosen, suggesting that at the current state of the art, it would be useful to employ more than one tracking scheme in routine analysis of such experiments. Diagnosis of tropical cyclone rainfall in the experiments shows support for previously proposed theoretical arguments that relate changes in warmer-world rainfall to the competing influences of increases in sea surface temperatures and increased carbon dioxide, providing further support for future projections of increased rainfall from tropical cyclones. Higher-resolution versions of some of the HWG models are now able to generate a good simulation of climatological Atlantic tropical cyclone formation, previously a difficult challenge for most models, and models of even higher resolution are now also able to simulate good climatological distributions of observed intensities.

A number of issues are identified by the HWG as requiring further investigation. The influence of the inclusion of an interactive ocean clearly is a further step needed to improve the realism of the results of the HWG experiments. Designing common experiments for models that include air-sea interaction is challenging, but they may be aided by the addition of a simple slab or mixed layer ocean with specific lateral fluxes to represent advective processes as a boundary condition. The inclusion of this simplified form of air-sea interaction will partially address the important issue of the inconsistency of the surface flux balance in experiments that employ specified SSTs and the resulting effects on variables such as potential intensity. Additionally, there is scope for the use of coupled ocean-atmosphere models in tropical cyclone simulation experiments (e.g., Vecchi et al. 2014). These experiments might be performed with or without selected modifications to the coupling methods, using so-called partial coupling (e.g., Ding et al. 2014), to enable a better understanding of how hurricanes influence the climate, as opposed to an understanding of how the climate influences hurricanes, as examined in the HWG experiments. There is also some scope for the use of ocean-only models in this topic (e.g., Vincent et al. 2013; Bueti et al. 2014).

A series of systematic experiments could be devised to examine the relative role of Atlantic versus global SST anomalies in the generation of tropical cyclones in the Atlantic basin (see Lee et al. 2011). Some results presented at the workshop indicate some support for the relative SST explanation of increases in tropical cyclone activity in the Atlantic in the past two decades, which could be further investigated by such experiments. A related topic is the relative role of future decadal and interannual variability in this basin when combined with the effects of anthropogenic warming. Patricola et al. (2014) investigate the possible effects of combinations of extreme phases of the AMM and ENSO. Figure 10 shows that strongly negative AMM activity, combined with strong El Niño conditions, inhibits Atlantic TC activity, but even with very positive AMM conditions, strong El Niño conditions still lead only to average Atlantic TC activity. Thus, any future climate change projection would ideally need to include information on changes in the periodicity and amplitude of the AMM and ENSO. Similarly, a factor that is not investigated in the HWG experiments is the role of changing atmospheric aerosols in the Atlantic basin (e.g., Villarini and Vecchi 2012, 2013). It would be possible to design a series of experiments to investigate this, similar to the HWG experiments.

Now that there is a critical mass of HWG experiments available for analysis, there may be some scope for using the experiments in an intercomparison process to determine if there are common factors that lead to improved simulations of both the mean atmospheric climate and tropical cyclone climatology. 
This would be facilitated by the use of novel analysis techniques associating the changes in tropical cyclone occurrence simulated in these experiments with changes in fundamental climate variables, along the lines of those already established by existing analysis of the HWG suite. Strong links between changes in tropical cyclone formation rate and fundamental measures of tropical circulation, and stronger quantification of these links, will ultimately lead to a clearer understanding of the relationship between tropical cyclones and climate.

ACKNOWLEDGMENTS. We wish to take this opportunity to recognize the essential contributions from participating modeling groups (U.S. DOE-NCAR CAM5.1, CMCC ECHAM5, CNRM, FSU COAPS, NOAA GFDL HiRAM, NASA GISS-Columbia University, NASA GSFC GEOS-5, Hadley Centre HadGEM3, JAMSTEC NICAM, MRI CGCM3, NCEP GFS, and WRF) that ran model experiments and furnished their data for analysis. We also appreciate the contributions of NOAA GFDL for hosting the meeting that led to this paper, the U.S. CLIVAR Project Office and UCAR JOSS for logistics support, and the U.S. CLIVAR funding agencies-NASA, NOAA, NSF, and DOEfor their sponsorship. The Texas Advanced Computing Center (TACC) at The University of Texas at Austin and the Texas A\&M Supercomputing Facility provided supercomputing resources used to perform portions of the simulations described in this paper. Portions of the work described in this paper were funded in part by the ARC Centre of Excellence for Climate System Science (Grant CE110001028); the U.S. DOE Grants DE-SC0006824, DE-SC0006684, and DE-SC0004966; the NOAA Grants NA11OAR4310154 and NA11OAR4310092; NSF AGS 1143959; and NASA Grant NNX09AK34G. E. Scoccimarro received funding from the Italian Ministry of Education, Universities and Research and the Italian Ministry of Environment, Land and Sea under the GEMINA project. The numerical experiments for NICAM and MRI-AGCM were performed on the Earth Simulator of JAMSTEC under the framework of the KAKUSHIN project funded by the Ministry of Education, Culture, Sports, Science and Technology (MEXT), Japan.

\section{REFERENCES}

Allen, M. R., and W. J. Ingram, 2002: Constraints on future changes in climate and the hydrologic cycle. Nature, 419, 224-232, doi:10.1038/nature01092.

Bender, M., T. Knutson, R. Tuleya, J. Sirutis, G. Vecchi, S. T. Garner, and I. Held, 2010: Modeled impact of anthropogenic warming on the frequency of intense Atlantic hurricanes. Science, 327, 454-458, doi:10.1126/science.1180568.
Bengtsson, L., K. I. Hodges, and M. Esch, 2007a: Tropical cyclones in a T159 resolution global climate model: Comparison with observations and re-analyses. Tellus, 59A, 396-416, doi:10.1111/j.1600 -0870.2007.00236.x.

— _ — _ - N. Keenlyside, L. Kornblueh, J.-J. Luo, and T. Yamagata, 2007b: How may tropical cyclones change in a warmer climate? Tellus, 59A, 539-561, doi:10.1111/j.1600-0870.2007.00251.x.

Broccoli, A. J., and S. Manabe, 1990: Can existing climate models be used to study anthropogenic changes in tropical cyclone climate? Geophys. Res. Lett., 17, 1917-1920, doi:10.1029/GL017i011p01917.

Bruyère, C. L., G. J. Holland, and E. Towler, 2012: Investigating the use of a genesis potential index for tropical cyclones in the North Atlantic basin. J. Climate, 25, 8611-8626, doi:10.1175/JCLI-D-11-00619.1.

Bueti, M. R., I. Ginis, L. M. Rothstein, and S. M. Griffies, 2014: Tropical cyclone-induced thermocline warming and its regional and global impacts. J. Climate, 27, 6978-6999, doi:10.1175 /JCLI-D-14-00152.1.

Camargo, S. J., 2013: Global and regional aspects of tropical cyclone activity in the CMIP5 models. J. Climate, 26, 9880-9902, doi:10.1175/JCLI-D-12-00549.1.

—, and S. E. Zebiak, 2002: Improving the detection and tracking of tropical cyclones in atmospheric general circulation models. Wea. Forecasting, 17, 1152-1162, doi:10.1175/1520-0434(2002)017<1152 :ITDATO >2.0.CO;2.

_- A. G. Barnston, and S. E. Zebiak, 2005: A statistical assessment of tropical cyclone activity in atmospheric general circulation models. Tellus, 57A, 589-604, doi:10.1111/j.1600-0870.2005.00117.x.

—, K. A. Emanuel, and A. H. Sobel, 2007a: Use of a genesis potential index to diagnose ENSO effects on tropical cyclone genesis. J. Climate, 20, 4819-4834, doi:10.1175/JCLI4282.1.

- A. H. Sobel, A. G. Barnston, and K. A. Emanuel, 2007b: Tropical cyclone genesis potential index in climate models. Tellus, 59A, 428-443, doi:10.1111 /j.1600-0870.2007.00238.x.

—, M. C. Wheeler, and A. H. Sobel, 2009: Diagnosis of the MJO modulation of tropical cyclogenesis using an empirical index. J. Atmos. Sci., 66, 3061-3074, doi:10.1175/2009JAS3101.1.

_-, M. Ting, and Y. Kushnir, 2013: Influence of local and remote SST on North Atlantic tropical cyclone potential intensity. Climate Dyn., 40, 1515-1520, doi:10.1007/s00382-012-1536-4.

—, M. K. Tippett, A. H. Sobel, G. A. Vecchi, and M. Zhao, 2014: Testing the performance of tropical cyclone genesis indices in future climates using 
the HiRAM model. J. Climate, 27, 9171-9196, doi:10.1175/JCLI-D-13-00505.1.

Chen, C.-T., T.-P. Tzeng, M. Wehner, Prabhat, and A. Kitoh, 2013: Tropical cyclone simulations in the very high-resolution global climate models. U.S. CLIVAR Hurricane Workshop, Princeton, NJ, Geophysical Fluid Dynamics Laboratory. [Available online at www.usclivar.org/sites/default/files/meetings /Chen_ChengTa_Hurricane2013.pdf.]

Daloz, A. S., F. Chauvin, and F. Roux, 2012a: Impact of the configuration of stretching and oceanatmosphere coupling on tropical cyclone activity in the variable-resolution GCM ARPEGE. Climate Dyn., 39, 2343-2359, doi:10.1007/s00382-012 -1561-3.

— — - K. Walsh, S. Lavender, D. Abbs, and F. Roux, 2012b: The ability of GCMs to simulate tropical cyclones and their precursors over the North Atlantic main development region. Climate Dyn., 39, 15591576, doi:10.1007/s00382-012-1290-7.

— , and Coauthors, 2015: Cluster analysis of downscaled and explicitly simulated North Atlantic tropical cyclone tracks. J. Climate, 28, 1333-1361, doi:10.1175/JCLI-D-13-00646.1.

Delworth, T. L., and M. E. Mann, 2000: Observed and simulated multidecadal variability in the Northern Hemisphere. Climate Dyn., 16, 661-676, doi:10.1007 /s003820000075.

Ding, H., R. J. Greatbatch, W. Park, M. Latif, V. A. Semenov, and X. Sun, 2014: The variability of the East Asian summer monsoon and its relationship to ENSO in a partially coupled climate model. Climate Dyn., 42, 367-379, doi:10.1007/s00382-012 -1642-3.

Dutton, J. F., C. J. Poulsen, and J. L. Evans, 2000: The effect of global climate change on the regions of tropical convection in CSM1. Geophys. Res. Lett., 27, 3049-3052, doi:10.1029/2000GL011542.

Elsner, J. B., S. E. Strazzo, T. H. Jagger, T. LaRow, and M. Zhao, 2013: Sensitivity of limiting hurricane intensity to SST in the Atlantic from observations and GCMs. J. Climate, 26, 5949-5957, doi:10.1175 /JCLI-D-12-00433.1.

Emanuel, K. A., 1986: An air-sea interaction theory for tropical cyclones. Part I: Steady-state maintenance. J. Atmos. Sci., 43, 585-605, doi:10.1175/1520 -0469(1986)043<0585:AASITF>2.0.CO;2.

_ 1988: The maximum intensity of hurricanes. J. Atmos. Sci., 45, 1143-1155, doi:10.1175/1520 -0469(1988)045<1143:TMIOH>2.0.CO;2.

_ 2010: Tropical cyclone activity downscaled from NOAA-CIRES Reanalysis, 1908-1958. J. Adv. Model. Earth Syst., 2 (1), doi:10.3894/JAMES.2010.2.1.
_ , 2013a: Downscaling CMIP5 climate models shows increased tropical cyclone activity over the 21st century. Proc. Natl. Acad. Sci. USA, 110, doi:10.1073 /pnas.1301293110.

— 2013b: Response of downscaled tropical cyclones to climate forcing: Results and interpretation. U.S. CLIVAR Hurricane Workshop, Princeton, NJ, Geophysical Fluid Dynamics Laboratory. [Available online at www.usclivar.org/sites/default/files /meetings/Emanuel_Kerry_Hurricane2013.pdf.]

— - and D. S. Nolan, 2004: Tropical cyclone activity and global climate. 26th Conf. on Hurricanes and Tropical Meteorology, Miami, FL, Amer. Meteor. Soc., 10A.2. [Available online at https://ams.confex. com/ams/26HURR/techprogram/paper_75463. htm.]

_- and A. Sobel, 2013: Response of tropical sea surface temperature, precipitation, and tropical cyclonerelated variables to changes in global and local forcing. J. Adv. Mod. Earth Sys, 5, 447-458, doi:10.1002 /jame.20032.

— , and - cited 2014: Tropical cyclone theory. Hurricane Working Group of U.S. CLIVAR. [Available online at www.usclivar.org/working-groups/hurricane /science/tropical-cyclone-theory.]

_, R. Sundararajan, and J. Williams, 2008: Hurricanes and global warming: Results from downscaling IPCC AR4 simulations. Bull. Amer. Meteor. Soc., 89, 347-367, doi:10.1175/BAMS-89-3-347.

_, S. Solomon, D. Folini, S. Davis, and C. Cagnazzo, 2013: Influence of tropical tropopause layer cooling on Atlantic hurricane activity. J. Climate, 26, 22882301, doi:10.1175/JCLI-D-12-00242.1.

Evans, J. L., 2013: Warming sea-surface temperature raises the bar for tropical cyclogenesis. U.S. CLIVAR Hurricane Workshop, Princeton, NJ, Geophysical Fluid Dynamics Laboratory. [Available online at www.usclivar.org/sites/default/files/meetings /Evans_Jenni_Hurricane2013.pdf.]

__, and J. J. Waters, 2012: Simulated relationships between sea surface temperatures and tropical convection in climate models and their implications for tropical cyclone activity. J. Climate, 25, 7884-7895, doi:10.1175/JCLI-D-11-00392.1.

Gray, W. M., 1979: Hurricanes: Their formation, structure and likely role in the tropical circulation. Meteorology over the Tropical Oceans, D. B. Shaw, Ed., Royal Meteorological Society, 155-218.

Gualdi, S., E. Scoccimarro, and A. Navarra, 2008: Changes in tropical cyclone activity due to global warming: Results from a high-resolution coupled general circulation model. J. Climate, 21, 5204-5228, doi:10.1175/2008JCLI1921.1. 
Haarsma, R. J., J. F. B. Mitchell, and C. A. Senior, 1993: Tropical disturbances in a GCM. Climate Dyn., 8, 247-257, doi:10.1007/BF00198619.

Held, I. M., and M. Zhao, 2011: The response of tropical cyclone statistics to an increase in $\mathrm{CO}_{2}$ with fixed sea surface temperatures. J. Climate, 24, 5353-5364, doi:10.1175/JCLI-D-11-00050.1.

Hodges, K. I., 1995: Feature tracking on a unit sphere. Mon. Wea. Rev., 123, 3458-3465, doi:10.1175/1520 -0493(1995)123<3458:FTOTUS>2.0.CO;2.

Holland, G. J., 1997: The maximum potential intensity of tropical cyclones. J. Atmos. Sci., 54, 2519-2541, doi:10.1175/1520-0469(1997)054<2519:TMPIOT >2 $0 . \mathrm{CO} ; 2$.

Horn, M., and Coauthors, 2014: Tracking scheme dependence of simulated tropical cyclone response to idealized climate simulations. J. Climate, 27, 9197-9213, doi:10.1175/JCLI-D-14-00200.1.

Kim, D., A. H. Sobel, E. D. Maloney, D. M. W. Frierson, and I.-S. Kang, 2011: A systematic relationship between intraseasonal variability and mean state bias in AGCM simulations. J. Climate, 24, 5506-5520, doi:10.1175/2011JCLI4177.1.

,-- , A. D. Del Genio, Y. Chen, S. J. Camargo, M.-S. Yao, M. Kelley, and L. Nazarenko, 2012: The tropical subseasonal variability simulated in the NASA GISS general circulation model. J. Climate, 25, 4641-4659, doi:10.1175/JCLI-D-11-00447.1.

Kim, H.-S., G. A. Vecchi, T. R. Knutson, W. G. Anderson, T. L. Delworth, A. Rosati, F. Zeng, and M. Zhao, 2014: Tropical cyclone simulation and response to $\mathrm{CO}_{2}$ doubling in the GFDL CM2.5 high-resolution coupled climate model. J. Climate, 27, 8034-8054, doi:10.1175/JCLI-D-13-00475.1.

Knapp, K. R., M. C. Kruk, D. H. Levinson, H. J. Diamond, and C. J. Neumann, 2010: The International Best Track Archive for Climate Stewardship (IBTrACS) unifying tropical cyclone data. Bull. Amer. Meteor. Soc., 91, 363-376, doi:10.1175/2009BAMS2755.1.

Knutson, T. R., 2013: Dynamical downscaling of tropical cyclone activity: An update on the use of GFDL hurricane model in multiple basins. U.S. CLIVAR Hurricane Workshop, Princeton, NJ, Geophysical Fluid Dynamics Laboratory. [Available online at www.usclivar.org /sites/default/files/meetings/Knutson_Thomas _Hurricane2013.pdf.]

— , and R. E. Tuleya, 2004: Impact of $\mathrm{CO}_{2}$-induced warming on simulated hurricane intensity and precipitation: Sensitivity to the choice of climate model and convective parameterization. J. Climate, 17, 3477-3495, doi:10.1175/1520-0442(2004)017<3477:IO CWOS $>2.0 . \mathrm{CO} ; 2$.
— J. J. Sirutis, S. T. Garner, I. M. Held, and R. E. Tuleya, 2007: Simulation of the recent multidecadal increase of Atlantic hurricane activity using an 18-km-grid regional model. Bull. Amer. Meteor. Soc., 88, 1549-1565, doi:10.1175/BAMS-88-10-1549.

$-, \ldots,-$, G. Vecchi, and I. Held, 2008: Simulated reduction in Atlantic hurricane frequency under twenty-first-century warming condition. Nat. Geosci., 1, 359-364, doi:10.1038/ngeo202.

— mate change. Nat. Geosci., 3, 157-163, doi:10.1038 /ngeo779.

— projections of twenty-first-century Atlantic hurricane activity: CMIP3 and CMIP5 model-based scenarios. J. Climate, 26, 6591-6617, doi:10.1175 /JCLI-D-12-00539.1.

Korty, R. L., S. J. Camargo, and J. Galewsky, 2012a: Tropical cyclone genesis factors in simulations of the Last Glacial Maximum. J. Climate, 25, 4348-4365, doi:10.1175/JCLI-D-11-00517.1.

,-- , and,$- 2012 \mathrm{~b}$ : Variations in tropical cyclone genesis factors in simulations of the Holocene epoch. J. Climate, 25, 8196-8211, doi:10.1175/JCLI -D-12-00033.1.

,-- , and — 2013: Environmental control of tropical cyclone genesis in paleoclimate simulations. U.S. CLIVAR Hurricane Workshop, Princeton, NJ, Geophysical Fluid Dynamics Laboratory. [Available online at www.usclivar.org/sites/default/files/ meetings/Korty_Robert_Hurricane2013.pdf.]

Kossin, J. P., and S. J. Camargo, 2009: Hurricane track variability and secular potential intensity trends. Climatic Change, 97, 329-337, doi:10.1007/s10584 -009-9748-2.

,$- \ldots$, and M. Sitkowski, 2010: Climate modulation of North Atlantic hurricane tracks. J. Climate, 23, 3057-3076, doi:10.1175/2010JCLI3497.1.

LaRow, T., Y.-K. Lim, D. Shin, E. Chassignet, and S. Cocke, 2008: Atlantic basin seasonal hurricane simulations. J. Climate, 21, 3191-3206, doi:10.1175/2007JCLI2036.1.

-, H. Wang, and I.-S. Kang, cited 2014: Seasonal forecasting of tropical cyclones. [Available online at www.usclivar.org/working-groups /hurricane/science/seasonal-forecasting-tropical -cyclones.]

Lavender, S. L., and K. J. E. Walsh, 2011: Dynamically downscaled simulations of Australian region tropical cyclones in current and future climates. Geophys. Res. Lett., 38, L10705, doi:10.1029/2011GL047499.

Lee, S.-K., D. B. Enfield, and C. Wang, 2011: Future impact of differential interbasin ocean warming 
on Atlantic hurricanes. J. Climate, 24, 1264-1275, doi:10.1175/2010JCLI3883.1.

Li, T., M. Kwon, M. Zhao, J.-S. Kug, J.-J. Luo, and W. Yu, 2010: Global warming shifts Pacific tropical cyclone location. Geophys. Res. Lett., 37, L21804, doi:10.1029/2010GL045124.

Lim, Y.-K., S. D. Schubert, O. Reales, M.-Y. Lee, A. M. Molod, and M. J. Suarez, 2015: Sensitivity of tropical cyclones to parameterized convection in the NASA GEOS-5 model. J. Climate, 28, 551-573, doi:10.1175 /JCLI-D-14-00104.1.

Maloney, E. D., and Coauthors, 2014: North American climate in CMIP5 experiments. Part III: Assessment of twenty-first-century projections. J. Climate, 27, 2230-2270, doi:10.1175/JCLI-D-13-00273.1.

Manganello, J. V., and Coauthors, 2012: Tropical cyclone climatology in a $10-\mathrm{km}$ global atmospheric GCM: Toward weather-resolving climate modeling. J. Climate, 25, 3867-3893, doi:10.1175 /JCLI-D-11-00346.1.

Mei, W., S. Xie, and M. Zhao, 2014: Variability of tropical cyclone track density in the North Atlantic: Observations and high-resolution simulations. J. Climate, 27, 4797-4814, doi:10.1175/JCLI-D-13-00587.1.

Menkes, C. E., M. Lengaigne, P. Marchesiello, N. C. Jourdain, E. M. Vincent, J. Lefevre, F. Chauvin, and J.-F. Royer, 2012: Comparison of tropical cyclogenesis indices on seasonal to interannual timescales. Climate Dyn., 38, 301-321, doi:10.1007/s00382-011 -1126-x.

Merlis, T. M., M. Zhao, and I. M. Held, 2013: The sensitivity of hurricane frequency to ITCZ changes and radiatively forced warming in aquaplanet simulations. Geophys. Res. Lett., 40, 4109-4114, doi:10.1002 /grl.50680.

Murakami, H., B. Wang, and A. Kitoh, 2011: Future change of western North Pacific typhoons: Projections by a $20-\mathrm{km}$-mesh global atmospheric model. J. Climate, 24, 1154-1169, doi:10.1175/2010JCLI3723.1.

__, R. Mizuta, and E. Shindo, 2012a: Future changes in tropical cyclone activity projected by multi-physics and multi-SST ensemble experiments using 60-kmmesh MRI-AGCM. Climate Dyn., 39, 2569-2584, doi:10.1007/s00382-011-1223-x.

— and Coauthors, 2012b: Future changes in tropical cyclone activity projected by the new high-resolution MRI-AGCM. J. Climate, 25, 3237-3260, doi:10.1175 /JCLI-D-11-00415.1.

—, B. Wang, T. Li, and A. Kitoh, 2013: Projected increase in tropical cyclones near Hawaii. Nat. Climate Change, 3, 749-754, doi:10.1038/nclimate1890.

— , P.-C. Hsu, O. Arakawa, and T. Li, 2014: Influence of model biases on projected future changes in tropical cyclone frequency of occurrence. J. Climate, 27, 2159-2181, doi:10.1175/JCLI-D-13-00436.1.

Oouchi, K., 2013: Tropical cyclone research with a global non-hydrostatic model. U.S. CLIVAR Hurricane Workshop, Princeton, NJ, Geophysical Fluid Dynamics Laboratory. [Available online at www.usclivar .org/sites/default/files/meetings/Oouchi_Kazuyoshi _Hurricane2013.pdf.]

—, J. Yoshimura, H. Yoshimura, R. Mizuta, S. Kusunoki, and A. Noda, 2006: Tropical cyclone climatology in a global-warming climate as simulated in a $20 \mathrm{~km}$-mesh global atmospheric model: Frequency and wind intensity analyses. J. Meteor. Soc. Japan, 84, 259-276, doi:10.2151/jmsj.84.259.

Patricola, C., R. Saravanan, and P. Chang, 2014: The impact of the El Niño-Southern Oscillation and Atlantic meridional mode on seasonal Atlantic tropical cyclone activity. J. Climate, 27, 5311-5328, doi:10.1175/JCLI-D-13-00687.1.

Po-Chedley, S., and Q. Fu, 2012: Discrepancies in tropical upper tropospheric warming between atmospheric circulation models and satellites. Environ. Res. Lett., 7, 04401, doi:10.1088/1748-9326/7/4/044018.

Ramsay, H., 2013: The effects of imposed stratospheric cooling on the maximum intensity of tropical cyclones in axisymmetric radiative-convective equilibrium. J. Climate, 26, 9977-9985, doi:10.1175 /JCLI-D-13-00195.1.

Rappin, E. D., D. S. Nolan, and K. A. Emanuel, 2010: Thermodynamic control of tropical cyclogenesis in environments of radiative-convective equilibrium with shear. Quart. J. Roy. Meteor. Soc., 136, 1954-1971, doi:10.1002/qj.706.

Rayner, N. A., D. E. Parker, E. B. Horton, C. K. Folland, L. V. Alexander, D. P. Rowell, E. C. Kent, and A. Kaplan, 2003: Global analyses of sea surface temperature, sea ice, and night marine air temperature since the late nineteenth century. J. Geophys. Res., 108, 4407, doi:10.1029/2002JD002670.

Reynolds, R. W., N. A. Rayner, T. M. Smith, D. C. Stokes, and W. Wang, 2002: An improved in situ and satellite SST analysis for climate. J. Climate, 15, 1609-1625, doi:10.1175/1520-0442(2002)015<1609:AIISAS >2 .0.CO;2.

Roberts, M., and Coauthors, 2015: Tropical cyclones in the UPSCALE ensemble of high-resolution global climate models. J. Climate, 28, 574-596, doi:10.1175 /JCLI-D-14-00131.1.

Royer, J.-F., F. Chauvin, B. Timbal, P. Araspin, and D. Grimal, 1998: A GCM study of the impact of greenhouse gas increase on the frequency of occurrence of tropical cyclones. Climatic Change, 38, 307-343, doi:10.1023/A:1005386312622. 
Saravanan, R., C. M. Patricola, and P. Chang, 2013: Hurricane simulations in a regional climate model. U.S. CLIVAR Hurricane Workshop, Princeton, NJ, Geophysical Fluid Dynamics Laboratory. [Available online at www.usclivar.org/sites/default/files /meetings/Saravanan_Ramalingam_Hurricane2013 .pdf.]

Schemm, J.-K., and L. Long, 2013: Dynamic hurricane prediction with the NCEP CFS CGCM. U.S. CLIVAR Hurricane Workshop, Princeton, NJ, Geophysical Fluid Dynamics Laboratory. [Available online at www.usclivar.org/sites/default/files/meetings /Long_Lindsey_Hurricane2013.pdf.]

Scoccimarro, E., S. Gualdi, G. Villarini, G. Vecchi, M. Zhao, K. Walsh, and A. Navarra, 2014: Intense precipitation events associated with landfalling tropical cyclones in response to a warmer climate and increased $\mathrm{CO}_{2}$. J. Climate, 27, 4642-4654, doi:10.1175 /JCLI-D-14-00065.1.

Servain, J., I. Wainer, J. P. McCreary, and A. Dessier, 1999: Relationship between the equatorial and meridional modes of climatic variability in the tropical Atlantic. Geophys. Res. Lett., 26, 485-488, doi:10.1029/1999GL900014.

Shaevitz, D. A., and Coauthors, 2014: Characteristics of tropical cyclones in high-resolution models in the present climate. J. Adv. Model. Earth Syst., 6, 1154-1172, doi:10.1002/2014MS000372.

Strachan, J., P.-L. Vidale, K. Hodges, M. Roberts, and M.-E. Demory, 2013: Investigating global tropical cyclone activity with a hierarchy of AGCMs: The role of model resolution. J. Climate, 26, 133-152, doi:10.1175/JCLI-D-12-00012.1.

Strazzo, S., J. B. Elsner, T. LaRow, D. J. Halperin, and M. Zhao, 2013a: Observed versus GCM-generated local tropical cyclone frequency: Comparisons using a spatial lattice. J. Climate, 26, 8257-8268, doi:10.1175 /JCLI-D-12-00808.1.

- - _ J. C. Trepanier, and K. A. Emanuel, 2013b: Frequency, intensity, and sensitivity to sea surface temperature of North Atlantic tropical cyclones in best-track and simulated data. J. Adv. Model. Earth Syst., 5, 500-509, doi:10.1002/jame.20036.

Sugi, M., and J. Yoshimura, 2004: A mechanism of tropical precipitation change due to $\mathrm{CO}_{2}$ increase. J. Climate, 17, 238-243, doi:10.1175/1520 -0442(2004)017<0238:AMOTPC>2.0.CO;2.

— A. Noda, and N. Sato, 2002: Influence of the global warming on tropical cyclone climatology: An experiment with the JMA global model. J. Meteor. Soc. Japan, 80, 249-272, doi:10.2151/jmsj.80.249.

—, H. Murakami, and J. Yoshimura, 2012: On the mechanism of tropical cyclone frequency changes due to global warming. J. Meteor. Soc. Japan, 90A, 397-408, doi:10.2151/jmsj.2012-A24.

Tang, B., and K. Emanuel, 2012: A ventilation index for tropical cyclones. Bull. Amer. Meteor. Soc., 93, 1901-1912, doi:10.1175/BAMS-D-11-00165.1.

— , and S. J. Camargo, 2014: Environmental control of tropical cyclones in CMIP5: A ventilation perspective. J. Adv. Model. Earth Syst., 6, 115-128, doi:10.1002/2013MS000294.

Taylor, K. E., R. J. Stouffer, and G. A. Meehl, 2012: An overview of CMIP5 and the experiment design. Bull. Amer. Meteor. Soc., 93, 485-498, doi:10.1175/BAMS -D-11-00094.1.

Timbal, B., J.-F. Mahfouf, J.-F. Royer, U. Cubasch, and J. M. Murphy, 1997: Comparison between doubled $\mathrm{CO}_{2}$ time-slice and coupled experiments. J. Climate, 10, 1463-1469, doi:10.1175/1520-0442(1997)010<1463 :CBDCTS>2.0.CO;2.

Ting, M., S. J. Camargo, and Y. Kushnir, 2013: North Atlantic hurricane potential intensity in CMIP5 models: Anthropogenic forcing versus Atlantic multi-decadal variability. U.S. CLIVAR Hurricane Workshop, Princeton, NJ, Geophysical Fluid Dynamics Laboratory. [Available online at www.usclivar .org/sites/default/files/meetings/Ting_Mingfang _Hurricane2013.pdf.]

,,-- C. Li, and Y. Kushnir, 2015: Natural and forced North Atlantic potential intensity changes in the CMIP5 models. J. Climate, 28, 3926-3942, doi:10.1175/JCLI-D-14-00520.1.

Tippett, M. K., S. J. Camargo, and A. H. Sobel, 2011: A Poisson regression index for tropical cyclone genesis and the role of large-scale vorticity in genesis. $J$. Climate, 24, 2335-2357, doi:10.1175/2010JCLI3811.1.

Tory, K., S. S. Chand, R. A. Dare, and J. L. McBride, 2013a: An assessment of a model-, grid-, and basinindependent tropical cyclone detection scheme in selected CMIP3 global climate models. J. Climate, 26, 5508-5522, doi:10.1175/JCLI-D-12-00511.1.

- - — J. L. McBride, H. Ye, and R. A. Dare, 2013b: Projected changes in late-twenty-first-century tropical cyclone frequency in 13 coupled climate models from phase 5 of the Coupled Model Intercomparison Project. J. Climate, 26, 9946-9959, doi:10.1175/JCLI -D-13-00010.1.

van Vuuren, D. P., and Coauthors, 2011: The representative concentration pathways: An overview. Climatic Change, 109, 5-31, doi:10.1007/s10584-011 -0148-z.

Vecchi, G. A., and B. Soden, 2007: Effect of remote sea surface temperature change on tropical cyclone potential intensity. Nature, 450, 1066-1071, doi:10 .1038 /nature06423. 
—, S. Fueglistaler, I. M. Held, T. R. Knutson, and M. Zhao, 2013: Impacts of atmospheric temperature changes on tropical cyclone activity. J. Climate, 26, 3877-3891, doi:10.1175/JCLI-D-12-00503.1.

_ , and Coauthors, 2014: On the seasonal forecasting of regional tropical cyclone activity. J. Climate, 27, 7994-8016, doi:10.1175/JCLI-D-14-00158.1.

Villarini, G., and G. A. Vecchi, 2012: Twenty-firstcentury projections of North Atlantic tropical storms from CMIP5 models. Nat. Climate Change, 2, 604-607, doi:10.1038/nclimate1530.

- , and — 2013: Projected increases in North Atlantic tropical cyclone intensity from CMIP5 models. J. Climate, 26, 3231-3240, doi:10.1175/JCLI -D-12-00441.1.

— — - T. R. Knutson, M. Zhao, and J. A. Smith, 2011: North Atlantic tropical storm frequency response to anthropogenic forcing: Projections and sources of uncertainty. J. Climate, 24, 3224-3238, doi:10.1175/2011JCLI3853.1.

- D. Lavers, E. Scoccimarro, M. Zhao, M. Wehner, G. Vecchi, T. Knutson, and K. Reed, 2014: Sensitivity of tropical cyclone rainfall to idealized global scale forcings. J. Climate, 27, 4622-4641, doi:10.1175/JCLI -D-13-00780.1.

Vimont, D. J., and J. P. Kossin, 2007: The Atlantic meridional mode and hurricane activity. Geophys. Res. Lett., 34, L07709, doi:10.1029/2007GL029683.

Vincent, E. M., G. Madec, M. Lengaigne, J. Vialard, and A. Koch-Larrouy, 2013: Influence of tropical cyclones on sea surface temperature seasonal cycle and ocean heat transport. Climate Dyn., 41, 2019-2038, doi:10.1007/s00382-012-1556-0.

Walsh, K., M. Fiorino, C. Landsea, and K. McInnes, 2007: Objectively determined resolution-dependent threshold criteria for the detection of tropical cyclones in climate models and reanalyses. J. Climate, 20, 2307-2314, doi:10.1175/JCLI4074.1.

_- M. Horn, S. Camargo, H. Murakami, H. Wang, and E. Scoccimarro, 2013a: Changes in future Southern Hemisphere tropical cyclone numbers. U.S. CLIVAR Variations, No. 11, CLIVAR, Washington, DC, 1-3.

— , S. Lavender, E. Scoccimarro, and H. Murakami, 2013b: Resolution dependence of tropical cyclone formation in CMIP3 and finer resolution models. Climate Dyn., 40, 585-599, doi:10.1007/s00382-012-1298-z.

Wang, H., and Coauthors, 2014a: How well do global climate models simulate the variability of Atlantic tropical cyclones associated with ENSO? J. Climate, 27, 5673-5692, doi:10.1175/JCLI-D-13-00625.1.

Wang, S., S. J. Camargo, A. H. Sobel, and L. M. Polvani, 2014b: Impact of the tropopause temperature on the intensity of tropical cyclones: An idealized study using a mesoscale model. J. Atmos. Sci., 71, 4333-4348, doi:10.1175/JAS-D-14-0029.1.

Wehner, M., and Coauthors, 2014: The effect of horizontal resolution on simulation quality in the Community Atmospheric Model, CAM5.1. J. Adv. Model. Earth Syst., 6, 980-997, doi:10.1002 /2013MS000276.

—, Prabhat, K. A. Reed, D. Stone, W. D. Collins, and J. Bacmeister, 2015: Resolution dependence of future tropical cyclone projections of CAM5.1 in the U.S. CLIVAR Hurricane Working Group idealized configurations. J. Climate, 28, 3905-3925, doi:10.1175 /JCLI-D-14-00311.1.

Wing, A. A., A. H. Sobel, and S. J. Camargo, 2007: The relationship between the potential and actual intensities of tropical cyclones on interannual time scales. Geophys. Res. Lett., 34, L08810, doi:10.1029 /2007GL030453.

Yamada, Y., and M. Satoh, 2013: Response of ice and liquid water paths of tropical cyclones to global warming simulated by a global nonhydrostatic model with explicit cloud microphysics. J. Climate, 26, 9931-9945, doi:10.1175/JCLI-D-13-00182.1.

Yoshimura, J., and M. Sugi, 2005: Tropical cyclone climatology in a high-resolution AGCM-Impacts of SST warming and $\mathrm{CO}_{2}$ increase. SOLA, 1, 133-136, doi:10.2151/sola.2005-035.

Zarzycki, C. M., and C. Jablonowski, 2014: A multidecadal simulation of Atlantic tropical cyclones using a variable-resolution global atmospheric general circulation model. J. Adv. Model. Earth Sys, 6, 805-828, doi:10.1002/2014MS000352.

Zhao, M., I. M. Held, S.-J. Lin, and G. A. Vecchi, 2009: Simulations of global hurricane climatology, interannual variability, and response to global warming using a $50-\mathrm{km}$ resolution GCM. J. Climate, 22, 6653-6678, doi:10.1175/2009JCLI3049.1.

—, G. Vecchi, E. Scoccimarro, S. Gualdi, H. Wang, A. Kumar, Y.-K. Lim, and S. Schubert, 2013a: Response of global tropical cyclone frequency to a doubling of $\mathrm{CO}_{2}$ and a uniform SST warmingA multi-model intercomparison. U.S. CLIVAR Hurricane Workshop, Princeton, NJ, Geophysical Fluid Dynamics Laboratory. [Available online at www.usclivar.org/sites/default/files/meetings /Zhao_Ming_Hurricane2013.pdf.]

— , and Coauthors, 2013b: Robust direct effect of increasing atmospheric $\mathrm{CO}_{2}$ concentration on global tropical cyclone frequency: A multi-model intercomparison. CLIVAR Variations, No. 11, CLIVAR, Washington, DC, 17-23. 


\section{AMS \\ RESEARCH APPLICATIONS HISTORY}

\section{CLIMATE}

\section{The Thinking Person's Guide to Climate Change}

\section{ROBERT HENSON}

This fully updated and expanded revision of The Rough Guide to Climate Change combines years of data with recent research. It is the most comprehensive overview of climate science, acknowledging controversies but standing strong in its stance that the climate is changing-and something needs to be done.

(c) 2014, PAPERBACK, 520 PAGES, ISBN: 978-1-935704-73-7 LIST $\$ 30$ MEMBER $\$ 20$

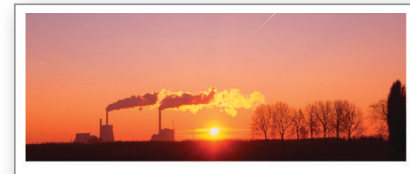

THE THINKING PERSON'S GUIDE TO CLIMATE CHANGE

ROBERT HENSON

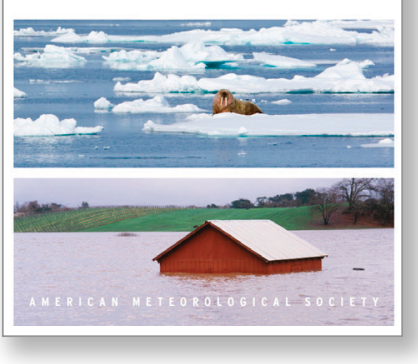

\section{AMS MEMBERS GET FREE}

GUIDES

\section{An Observer's Guide to Clouds and Weather:}

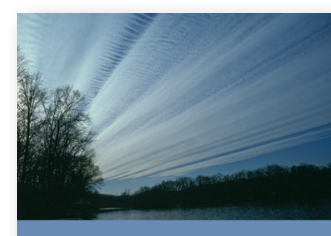

AN OBSERVER'S GUIDE

CLOUDS AND WEATHER

A NORTHEASTERN PRIMER ON PREOICTION

A Northeastern

Primer on Prediction

TOBY CARLSON, PAUL KNIGHT, AND CELIA WYKOFF

With help from Penn State experts, start at the beginning and go deep. This primer intended for both serious enthusiasts and new meteorology students, will leave you with both refined observation skills and an understanding of the complex science behind the weather: the ingredients for making reliable predictions of your own. It connects fundamental meteorological concepts with the processes that shape weather patterns, and will make an expert of any dedicated reader.

(c) 2014, PAPERBACK, 210 PAGES,

ISBN: 978-1-935704-58-4 LIST \$30 MEMBER $\$ 20$

\section{Eloquent Science:}

Climate Conundrums:

William B. Gail

समी 190

CLIMATE CONUNDRUMS

What the Climate Debate Reveals About Us
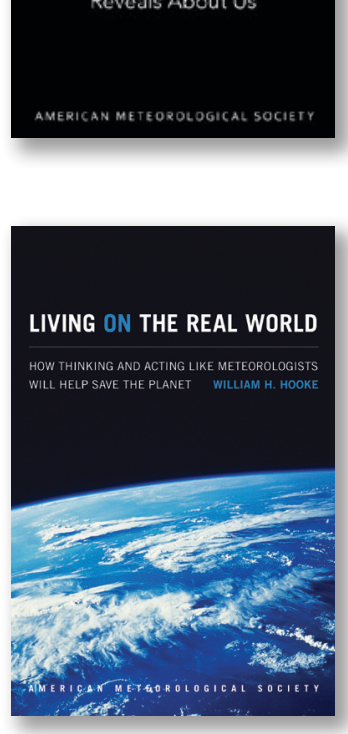

\section{Living on the} Real World:

How Thinking and Acting Like Meteorologists Will Help Save the Planet WILLIAM H. HOOKE

Meteorologists focus on small bits of information while using frequent collaboration to make decisions. With climate change a reality, William $\mathrm{H}$. Hooke suggests we look to the way meteorologists operate as a model for how we can solve the 21st century's most urgent environmental problems.

(c) 2014, PAPERBACK, 272 PAGES, ISBN 978-1-935704-56-0 LIST \$30 MEMBER \$22

\section{A Practical Guide to Becoming a Better Writer, Speaker, and Atmospheric Scientist DAVID M. SCHULTZ \\ The ultimate communications manual for undergraduate and graduate students as well as researchers in the atmospheric sciences and their intersecting disciplines. \\ (c) 2009, PAPERBACK, 440 PAGES, ISBN 978-1-878220-91-2}

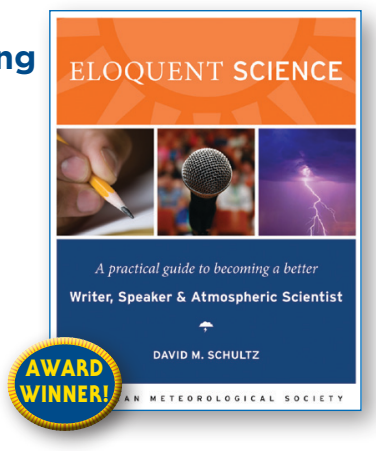

LIST \$45 MEMBER \$30

\section{TEXTBOOK}

\section{Midlatitude Synoptic Meteorology: Dynamics, Analysis, and Forecasting GARY LACKMANN}

This textbook links theoretical concepts to modern technology, facilitating meaningful application of concepts, theories, and techniques using real data.

(c)2011, PAPERBACK, 360 PAGES, ISBN 978-1-878220-10-3

LIST \$100 MEMBER \$75 STUDENT MEMB. \$65

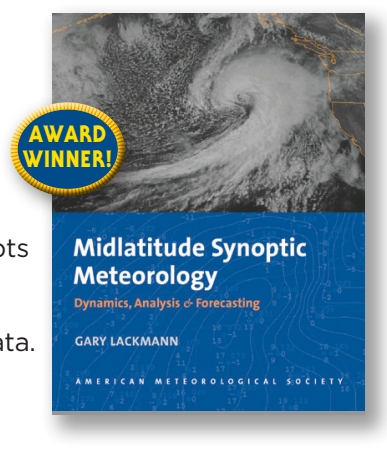

Midlatitude Synoptic Meteorology Teaching CD More than 1,000 PowerPoint Slides.

(c) 2013, CD, ISBN 978-1-878220-27-1 LIST \$100 MEMBER \$75 


\section{SHIPPING + DISCOUNTS AT BOOKSTORE.AMETSOC.ORG}

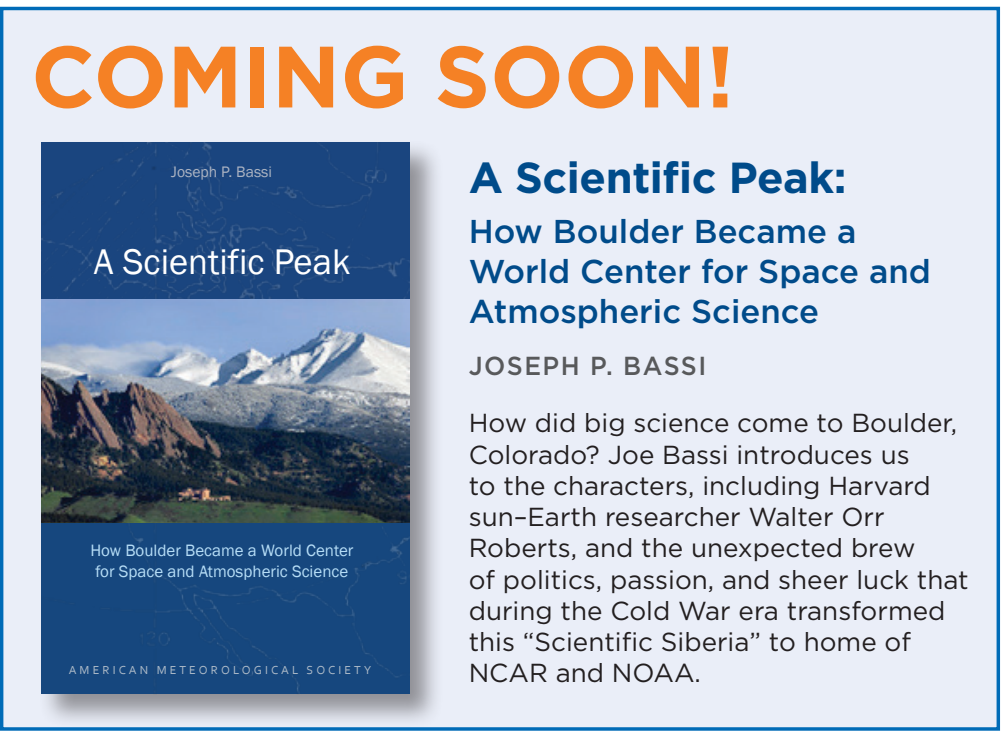

METEOROLOGICAL MONOGRAPH SERIES

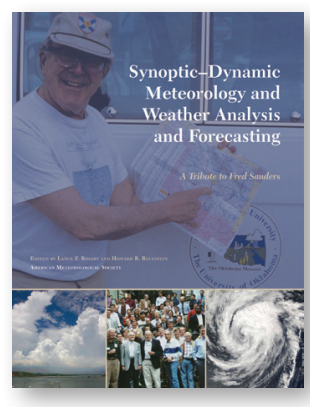

\section{Synoptic-Dynamic} Meteorology and Weather Analysis and Forecasting:

\section{A Tribute to}

Fred Sanders

EDITED BY LANCE F.

BOSART AND HOWARD B. BLUESTEIN

(C) 2008, HARDCOVER, 440 PAGES, VOL. 33, NO. 55 , ISBN 978-1-878220-84-4

LIST \$120 MEMBER $\$ 80$ STUDENT MEM. $\$ 60$

\section{HISTORY}

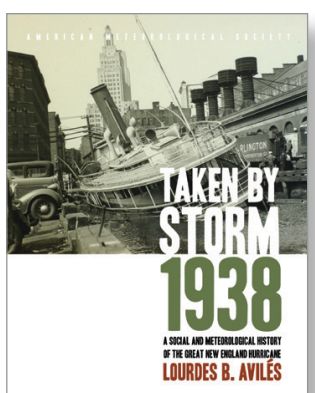

\section{Taken by Storm, 1938:}

\section{A Social and}

Meteorological

History of the Great

New England Hurricane LOURDES B. AVILÉS

The science behind the 1938 Hurricane, which hit New England unannounced, is presented here for the first time along with new data that sheds light on the motivations of the Weather Bureau forecasters. This compelling history successfully weaves science, historical accounts, and social analyses to create a comprehensive picture of the most powerful and devastating hurricane to hit New England to date.

(c) 2013, HARDCOVER, 288 PAGES, ISBN: 978-1-878220-37-0 LIST $\$ 40$ MEMBER $\$ 30$

\section{Father Benito Viñes:}

The 19th-Century Life

and Contributions of a

Cuban Hurricane Observer and Scientist

LUIS E. RAMOS GUADALUPE TRANSLATED BY OSWALDO GARCIA

Before Doppler radar and weather broadcasts, Spanish Jesuit Benito Viñes (1837-1893) spent decades observing the skies at Belen Observatory in colonial Cuba. Nicknamed "the Hurricane Priest," Viñes taught the public about the weather and developed the first network of weather observation stations in the Caribbean, groundwork for the hurricane warning systems we use today.
Northeast Snowstorms (Volume I: Overview, Volume II: The Cases) PAUL J. KOCIN AND LOUIS W. UCCELLINI (c) 2004, TWO HARDCOVER VOLS. PLUS DVD,

VOL. 32, NO. 54, ISBN 978-1-878220-64-6

LIST \$100 MEMBER \$80 STUDENT MEM. $\$ 60$

\section{Severe Convective Storms}

EDITED BY CHARLES A. DOSWELL III (c) 2001, HARDCOVER, 570 PAGES,

VOL. 28, NO. 50

ISBN 978-1-878220-41-7

LIST \$110 MEMBER \$90 STUDENT MEM. $\$ 75$

\section{(c) 2014, PAPERBACK, 172 PAGES}

ISBN: 978-1-935704-62-1 LIST \$20 MEMBER \$16

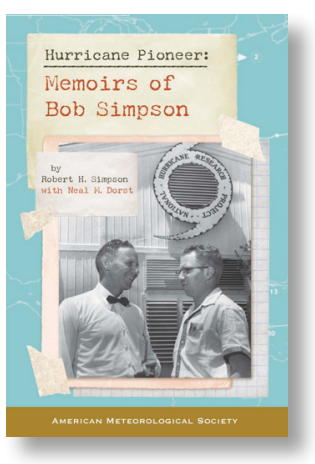

\section{Hurricane Pioneer:} Memoirs of Bob Simpson ROBERT H. SIMPSON AND NEAL DORST

In 1951, Bob Simpson rode a plane into a hurricane-just one of the many pioneering exploits you'll find in these memoirs. Bob and his wife Joanne are meteorological icons: Bob was the first director of the National Hurricane Research Project and a director of the National Hurricane Center. He helped to create the Saffir-Simpson Hurricane Scale; the public knows well his Categories 1-5. Proceeds from this book help support the AMS's K. Vic Ooyama Scholarship Fund.

(c) 2015, PAPERBACK, 156 PAGES ISBN: 978-1-935704-75-1 LIST \$25 MEMBER \$20 


\section{SEVERE CDNVECTIVE STORMS}

Meterralggical Munggraph No. 50

Edited by Charles Doswell III

\section{Severe Convective Storms}

Charles A. Doswell III, Editor

American Meteorological Society
This volume is a collection of 13 review papers by a distinguished group of scientists, providing a summary of the current scientific understanding of convective storms and the weather they produce, as well as showing how that understanding works in forecasting practice. The volume is loaded with outstanding illustrations, and is destined to become one of the most widely referred-to books on convection and convective processes.

\section{SEVERE CONUECTIVE STORMS, Meteorological Monograph No. 50}

ISBN 1-878220-41-1, 576 pp., hardbound, $\$ 110$ list/\$90 member, student member price: $\$ 75$.

\section{ORDER ONLINE}

www.ametsoc.org/amsbookstore

or see the order form in the back of this issue. 